\author{
C.-W. von der Lieth ${ }^{\mathrm{a}}$ \\ H.-C. Siebert ${ }^{\mathrm{b}}$ \\ T. Kožár ${ }^{\mathrm{c}, \mathrm{d}}$ \\ M. Burchert ${ }^{\mathrm{b}}$ \\ M. Frank ${ }^{\text {a }}$ \\ M. Gilleron ${ }^{\mathrm{e}}$ \\ H. Kaltner ${ }^{\text {b }}$ \\ G. Kayser ${ }^{\text {a }}$ \\ E. Tajkhorshid ${ }^{\text {a }}$ \\ N.V. Bovin ${ }^{\mathrm{f}}$ \\ J.F.G. Vliegenthart ${ }^{\mathrm{g}}$ \\ H.-J. Gabius ${ }^{\mathrm{b}}$
}

a Deutsches Krebsforschungszentrum, Zentrale Spektroskopie, Heidelberg, and

Institut für Physiologische Chemie,

Tierärztliche Fakultät,

Ludwig-Maximilians-Universität,

München, Germany

Glyco-Design, Toronto, Canada;

${ }^{d}$ Department of Biophysics, Institute of Experimental Physics, Slovak Academy of Sciences, Kosice, Slovakia;

Institut de Pharmacologie et de Biologie Structurale du CNRS, Toulouse, France;

Shemyakin Institute of Bioorganic

Chemistry, Russian Academy of Sciences,

Moscow, Russia;

g Bijvoet Center for Biomolecular Research, Department of Bio-Organic Chemistry,

Utrecht University, Utrecht,

The Netherlands

\section{Lectin Ligands: New Insights into Their Conformations and Their Dynamic Behavior and the Discovery of Conformer Selection by Lectins}

\section{Key Words}

Lectin $\cdot$ NMR spectroscopy $\cdot$ Crystallography $\cdot$ Molecular modeling $\cdot$ Drug design

\begin{abstract}
The mysteries of the functions of complex glycoconjugates have enthralled scientists over decades. Theoretical considerations have ascribed an enormous capacity to store information to oligosaccharides. In the interplay with lectins sugar-code words of complex carbohydrate structures can be deciphered. To capitalize on knowledge about this type of molecular recognition for rational marker/drug design, the intimate details of the recognition process must be delineated. To this aim the required approach is garnered from several fields, profiting from advances primarily in X-ray crystallography, nuclear magnetic resonance spectroscopy and computational calculations encompassing molecular mechanics, molecular dynamics and homology modeling. Collectively considered, the results force us to jettison the preconception of a rigid ligand structure. On the contrary, a carbohydrate ligand may move rather freely between two or even more low-energy positions, affording the basis for conformer selection by a lectin. By an exemplary illustration of the interdisciplinary approach including up-to-date refinements in carbohydrate modeling it is underscored why this combination is considered to show promise of fostering innovative strategies in rational marker/drug design.
\end{abstract}

Abbreviations used in this paper:

$\mathrm{CIDNP}=$ Chemically induced dynamic nuclear polarization; $\mathrm{NMR}=$ nuclear magnetic resonance; $\mathrm{NOE}=$ nuclear Overhauser effect; $\operatorname{trNOE}=$ transferred nuclear Overhauser effect; 2D/3D = two-/three-dimensional.

Dedicated to Prof. F. Cramer on the occasion of his 75th birthday.

\section{Introduction}

The astounding complexity of glycosylation raises the impression at first sight that revealing the enigmas of complex carbohydrate structures and functions can be the scientist's version of 'Mission: Impossible'. Definitely, such concern can be allayed immediately and convincingly.

\begin{tabular}{ll}
\hline KARGER & ( 1998 S. KargerAG, Basel \\
Fax+4161306 12 34 & 0001-5180/98/1614-0091\$15.00/0 \\
$\begin{array}{l}\text { E-Mail karger@ karger.ch } \\
\text { www.karger.com }\end{array}$ & $\begin{array}{l}\text { Accessible online at: } \\
\text { http:/BioMedNet.com/karger }\end{array}$
\end{tabular}

Dr. C.-W. von der Lieth

Deutsches Krebsforschungszentrum, Zentrale Spektroskopie Im Neuenheimer Feld 280, D-69120 Heidelberg (Germany)

Tel. +496221 424541, Fax +4962214554

E-Mail W.vonderLieth@DKFZ-Heidelberg.de 
Building a solid foundation, the efforts in this area over several decades have primarily focused on glycoconjugate purification and cataloguing [Montreuil, 1995; Sharon, 1998]. Without precise knowledge about the rules of biochemical glycosylation it would be a rather audacious endeavor to deal with the issue of carbohydrates as molecules in search of a function [Cook, 1986, 1995]. The recent developments make it reasonable to endorse the notion that we have entered a stage in which we deliberately work on hypotheses for the multipurpose oligosaccharides. Indeed, elegant and efficient strategies have been established for glycoconjugate analysis [Hounsell, 1997; Geyer and Geyer, 1998]. The intricacies of enzymatic protein and lipid glycosylation are being steadily unraveled [Brockhausen and Schachter, 1997; Kopitz, 1997; Pavelka, 1997; Varki, 1998] and the ideas about the actual properties imparted by the presence of oligosaccharides on the carrier become more and more refined [Gahmberg and Tolvanen, 1996; Hooper et al., 1997; Kopitz, 1997; Kresse, 1997; Sharon and Lis, 1997]. Thus, we are witnessing the shaping of the career of this structural part of cellular glycoconjugates from an assumed functionally inert compound, recently ironically referred to as a 'second-class citizen in biomedicine' [von der Lieth et al., 1997a], to a crucial player in protein and cell functions. As attested by the potency of glycan chains on proteins to elicit antibody production, what is still considered as a troublesome origin of epitope cross-reactivity by glycoproteins [Feizi and Childs, 1987], carrier-bound oligosaccharides can be well accessible for appropriate receptors such as an immunoglobulin. The spatial accessibility is the basis to allow monitoring of occurrence of distinct carbohydrate epitopes by antibodies or lectins. The latter class of sugar receptors harbors neither antibodies nor enzymes with activity in carbohydrate remodeling or metabolism and has shared the scientific fate of complex carbohydrates also over decades as proteins in search of a function [Kocourek, 1986; Sharon and Lis, 1987; Gabius, 1994].

Commonly, plant and invertebrate lectins are employed as tools for glycoconjugate analysis and localization [Lotan and Nicolson, 1979; Spicer and Schulte, 1992; Gabius and Gabius, 1993; Danguy et al., 1994, 1998; Danguy, 1995; Cummings, 1997; Rhodes and Milton, 1998]. Localization in tissue sections, e.g. to detect developmental or malignancy-associated changes in glycoconjugate display, similarly takes advantage of this panel of probes [Mann, 1988; Bourillon and Aubery, 1989; Hakomori, 1989, 1998; Varki and Marth, 1995; Kannan and Nair, 1997; Brinck et al., 1998; Brockhausen et al., 1998; Mann and Waterman, 1998; Zschäbitz, 1998]. Its proven versatility not only fuels work on elucidation of the functions of these proteins

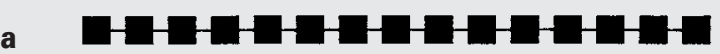

b

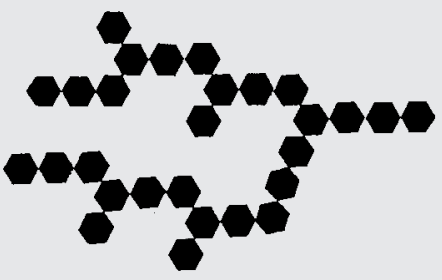

Fig. 1. Schematic representation of the geometric arrangement of monomers in oligo- and polymeric biomolecules establishing the commonly linear structures of nucleic acids and proteins (a). In contrast to these two types of biomolecules formation of the glycosidic bond in oligosaccharides which can involve different hydroxyl groups (see fig. 2) affords the capacity to generate branched structures (b).

in plants and invertebrates such as the horseshoe crab [Etzler, 1985; Vasta, 1992; Peumans and van Damme, 1995; Gabius, 1997a; Rüdiger, 1997, 1998]. Moreover, the description of apparently strictly and exquisitely regulated occurrence of distinct binding sites for these body-foreign proteins poignantly points to the possibility that their expression is not just guided by chance. Compelling evidence documents that functional equivalents of these lectins used as laboratory tools are expressed in animals [Ashwell and Harford, 1982; Barondes, 1984; Gabius, 1987, 1991, 1997a, b; Sharon and Lis, 1989; Zanetta, 1997, 1998; Kaltner and Stierstorfer, 1998]. Owing to mastering the tasks to prepare synthetic oligosaccharides and to conjugate them to histochemically inert carrier polymers the produced neoglycoconjugates have already become an approved part in investigations to track down animal lectins [Stowell and Lee, 1980; Gabius and Bardosi, 1991; Gabius et al., 1993; Lee and Lee, 1994; Bovin and Gabius, 1995; André et al., 1997; Schmidt, 1997]. Their expression is decisive for the credibility of the concept of a productive protein-carbohydrate interaction, the lectins assuming the assignment to read the information of the sugar code. Similar to oligoand polymers of nucleotides and amino acids which productively interact with proteins it is therefore justified to ascribe information-storing potential also to oligosaccharides. This aspect reveals the diversity of glycan structures in a different light, changing the assessment of their complexity from predominantly phenomenological cataloguing to listing of determinants with a potential for recognitive inter- 
<smiles>OC[C@H]1OCC[C@H](O)[C@H](O)[C@H]1O</smiles>
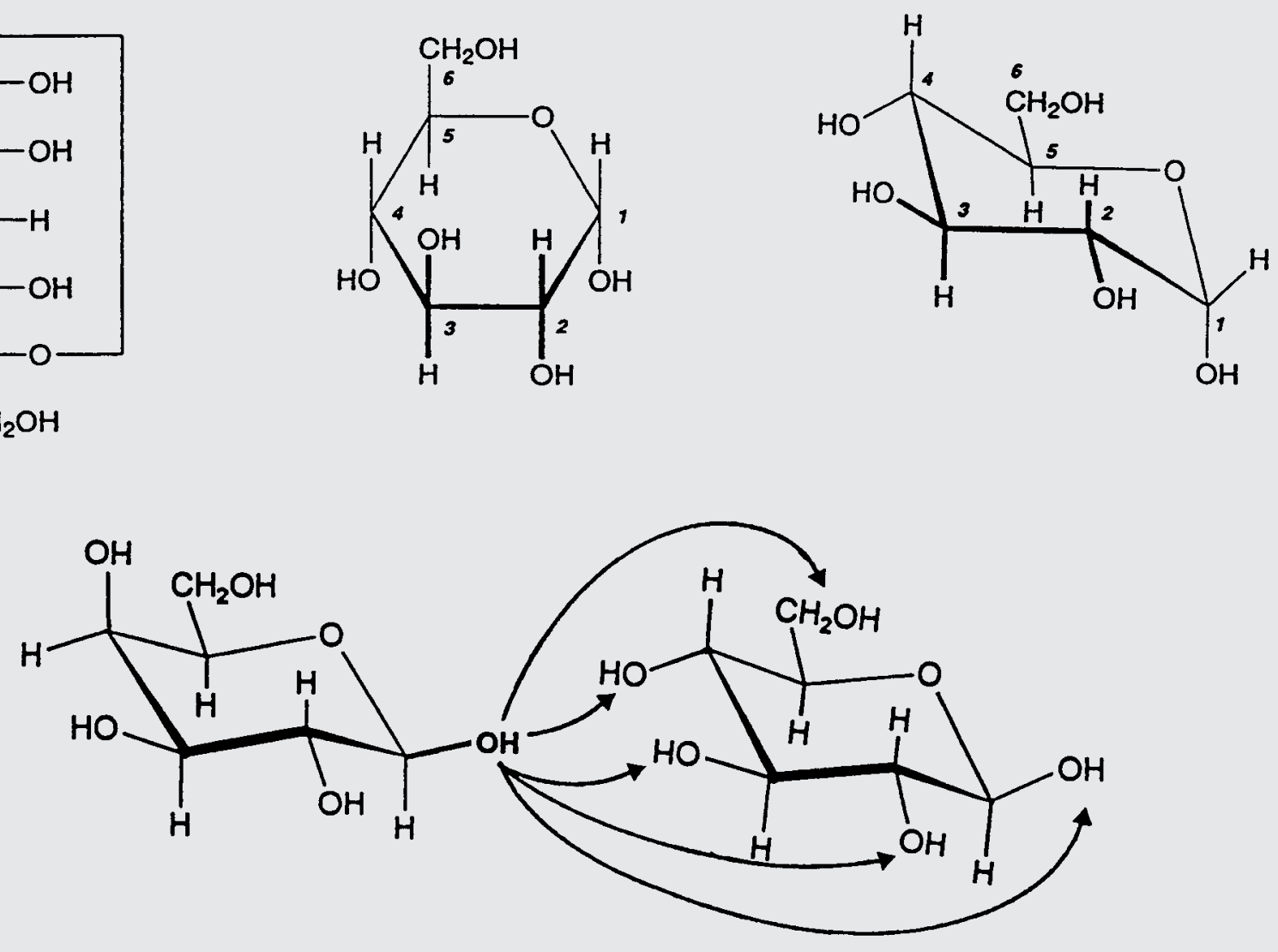

Fig. 2. Diagram of the various depictions of the structure of a monosaccharide ( $\alpha$ - $D$-glucose; top) as intramolecular hemiacetal without explicit indication of the relative positions of the atomic groups in space (left) and in the Haworth projection (center). This method defines these positions relative to the plane of the ring which is perpendicular to the plane of the paper with the heavy line on the ring closest to the reader. The most refined form of structural representation of the preferred conformation is the chair with the equatorial and axial substituents (right). Diagram of the structural basis for the generation of linear and branched oligomers (bottom), shown in figure 1. A glycosidic linkage involving the $\beta$-anomeric hydroxyl group of the left monosaccharide ( $D$-galactose) can theoretically be formed with any hydroxyl group of the acceptor ( $D$-glucose), yielding $\beta 1-1, \beta 1-2, \beta 1-3, \beta 1-4$ or $\beta 1-6$ connections (arrows). A disaccharide with a $\beta 1,2$ linkage between two $D$-galactose units is exemplarily shown in figure 3 .

play. A hallmark of such sequences is their often occurring branching, which is only rarely encountered in proteins and nucleic acids (fig. 1). From the point-of-view of storage of information, this structural feature has enormous consequences [Laine, 1997].

\section{The Structural Basis of the Sugar Code}

In contrast to peptide and 5', $3^{\prime}$-phosphodiester bonds the chemical formation of the glycosidic linkage between two monosaccharides can yield several structurally different disaccharides. Due to the eminent importance of this feature it is instructive to recall some basic biochemistry. Visualizing the most common hexose $D$-glucose in its stable form as intramolecular hemiacetal, the presentation of five hydroxyl groups explains the potential for structural variability of oligomers and for branch formation (fig. 2, upper part). When a monosaccharide engages its anomeric hydroxyl group ( $\alpha$ - or $\beta$-form) in a glycosidic linkage, the covalent connection to the second hexopyranose ring can theoretically be made via the indicated five positions (fig.2, bottom). Further elongation of the chain from the nonreducing section can theoretically use any combination of 


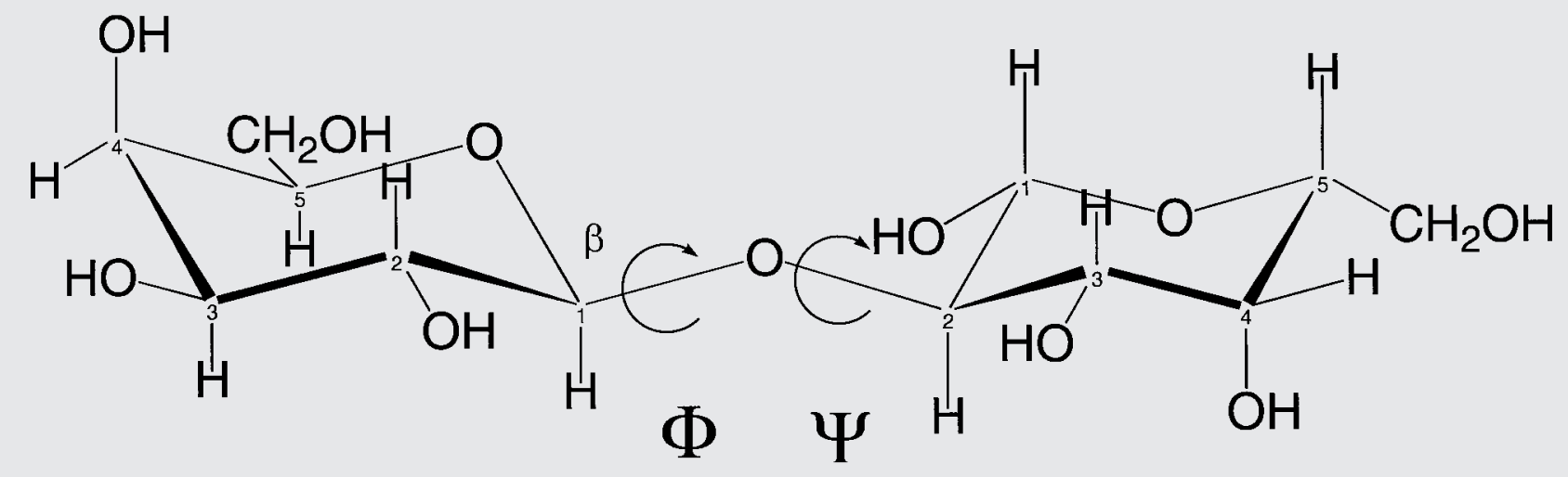

Fig. 3. Structural representation of the disaccharide gal- $\beta 1,2$-gal with emphasis on depiction of the origin of conformational flexibility by independent rotations about the dihedral angles $\phi$ and $\psi$ of the glycosidic bond.

available hydroxyl groups. Consequently, a chain structure can readily obtain branches, schematically drawn in figure $1 \mathrm{~b}$, by further involvement of the free and spatially accessible groups. The factors of variable anomeric configuration and linkage position as well as the introduction of branching points at each sugar unit contribute markedly to let the numbers of the theoretically possible repertoire of isomeric structures skyrocket. Respective calculations demonstrate that carbohydrates surpass by far the coding potential of amino acids [Laine, 1997]. In detail, $6.4 \times 10^{7}$ hexapeptides can be generated from twenty amino acids. Applying permutational calculations to a set of only six $D$-hexoses, $1.05 \times 10^{12}$ different linear or branched hexasaccharides can be imagined. Allowing the size of the monomer vocabulary to reach twenty letters to equal amino acids, a total of $1.44 \times 10^{15}$ isomers will be reached [Laine, 1997]. However, it is pertinent to point out that the enzymatic machinery of cellular glycosylation sets limits to the actual production of any theoretically devisable permutation restricting the size of the isomer pool [Brockhausen and Schachter, 1997]. Enzymatic reactions, however, can also serve to diversify established oligosaccharides which thereby acquire nonrandom substitutions. As a balancing factor to the noted restriction and therefore as source for new variability, the occurrence of uncommon saccharide derivatives by sitespecific modifications, e.g. sulfation, O-acetylation or phos- phorylation, has already proven functionally relevant as docking points for lectins [Varki, 1996; Hooper et al., 1997; Sharon and Lis, 1997]. In summary, it is beyond doubt that the hardware of the sugar code, i.e. the monosaccharide letters of the third alphabet of life, establishes the prerequisites for the 'most complex known chemical code in a short sequence among all biological oligomers' [Laine, 1997].

When a protein such as a lectin recognizes specific code elements, it does no longer suffice to deliberate only on the primary structure of the ligand. After the elaboration of analytical methods to reliably unravel the sequence the next challenge is posed by the necessity for the description of the conformation and the structural flexibility of oligosaccharides in order to comprehend their ligand properties. When the structure of two linked hexopyranose rings is carefully inspected, this problem turns out to be less complicated than initially thought. The main source of spatial alterations for saccharides resides in the bonds of the glycosidic linkage due to the rather rigid ring structure with their pronounced energetic preference for the chair conformation. As shown in figure 3, both dihedral torsion angles $\phi$ and $\psi$ of these two exocyclic bonds can be independently varied, thereby altering the relative positions of the two rings. By letting the thumbs of each hand touch in the appropriate angle and then by moving each hand independently without losing the contact of the thumbs, the reader 
can easily visualize the principle of $\phi, \psi$-flexibility with his hands. The questions immediately arise of which angle positions will be energetically preferred for individual oligomers, to what extent conformational flexibility will exist and whether binding of the ligand to a receptor may distort predominant angle positions. To assail the solution of these problems, whose acquisition will have far-reaching consequences for drug design [Gabius, 1998], a combined application of computer modeling and nuclear magnetic resonance (NMR) spectroscopy is essential.

\section{Oligosaccharide Flexibility: No Longer a Hidden Aspect of the Ligand's Personality}

The two torsion angles $\phi$ and $\psi$ define the conformational space for any disaccharide. Drawing the analogy to topographical maps, the area of a diagrammatic $\phi, \psi$-representation receives its third dimension not by altitude, but by the energy content of each conformation, defined by a certain $\phi, \psi$-combination. The total potential energy for any $\phi$, $\psi$-set can be calculated, if the individual energetic contributions are adequately taken into consideration. Factors to be reckoned with include e.g. bond deformations, valence angle distortions and nonbonded interactions. They are carefully compiled and a set of equations is developed which establish a force field, as reviewed recently [Pérez et al., 1994; Woods et al., 1995; Woods, 1996; Imberty, 1997; Rasmussen, 1997; von der Lieth et al., 1997b]. To limit the number of the otherwise prohibitively long series of calculations, a grid is established by drawing lines with a regular distance, e.g. $20^{\circ}$, into the $\phi, \psi$-area marking selected torsion angle combinations (fig. $4 \mathrm{a}, \mathrm{b}, 5 \mathrm{a}-\mathrm{c}$ ). At this stage, inspection of the other rotatable bonds in the molecule, e.g. of hydroxyl groups, comes into play. The energetic description of low-energy configurations becomes more and more refined. To obtain the desired topographical illustration for each grid intersection, all rotatable bonds in the molecule besides the fixed $\phi, \psi$-combination will have to be examined. By randomly generating an ensemble of internal conformers, which usually is in the order of magnitude of thousands, and evaluating the relative energy content in each case, this random walk of rotatable groups provides data material for further processing. The nondirected movement of the pendant groups has prompted to refer to this method as random walk molecular mechanics [Kožár et al., 1990]. In the next step, an energy cutoff limit is defined to set bounds to the number of calculations for optimization of the so far randomly produced angle combinations at each grid point. In other words, one is not interested to expend time and efforts on high-energy conformations, when the aim is to infer the topology of low-energy constellations. At the end of these calculations the number of fixed coordinates of the molecules' geometry is cut down to the bonds of the ring and the $\phi, \psi$-torsion angles of the grid point. The next step in the procedure can thus be readily predicted. Following the analysis of the rotatable linkages of $\mathrm{OH}$ and $\mathrm{CH}_{2} \mathrm{OH}$ groups (see fig. 2) optimization of the molecules' geometry moves to the other internal bonds except for the grid-defined two angle positions. The final results of these calculations are the three- (3D) or two-dimensional (2D) maps, referred to as adiabatic or relaxed conformational energy maps (fig. 4a, b, 5a-c). These maps reveal that the conformational space of a disaccharide can be visualized as a hilly landscape. Remarkably, not just one, but several low energy positions can be inferred for the two inspected digalactosides. Similarly intriguing is the answer to the question of whether the position of the glycosidic linkage will alter the energy profile. When the maps for two digalactosides which differ only in their linkage points (i.e. $1,2$ vs. 1,3$)$ are compared ( $\varepsilon=1.5$, fig. 4 a, b, 5a), it is evident that the shape of the central low-energy valley is different. Disparities in the presentation of functional groups due to the change in linkage point and/or in the conformational behavior may explain the more than 2-fold difference in inhibitory capacity of the two digalactosides in a binding assay for a plant lectin [Lee et al., 1992, 1994; Galanina et al., 1997]. Overall, these relaxed maps underscore the importance of exploring the conformational space of an oligosaccharide. The term 'relaxed' indicates that no artificial strain is imposed in the molecules' geometry to simulate the conformational behavior as realistically as possible. It also reminds one of the initial grid constraint which remains to be considered.

At this stage, the ring geometry and the rotatable pendant groups have been optimized. To prevent being deluded into the notion that the description of the correlation between conformation and energy content is complete, the final step to alleviate the inherent $\phi, \psi$-constraint must not be neglected. The necessity for lifting the grid-imposed restrictions becomes evident, when a worst-case scenario is devised. If an actual energy minimum conformation is not located in the vicinity of a grid point, it can be missed, reducing the value of the calculations. To completely simulate the conformational behavior the final optimization should allow $\phi, \psi$-angles to leave the fixed grid points. Low-energy conformations will now appear as clusters (shown in fig. 4, 5) after energy minimization without constraint [Kožár and von der Lieth, 1997]. Again alluding to the analogy of a hilly countryside, these clusters can be 


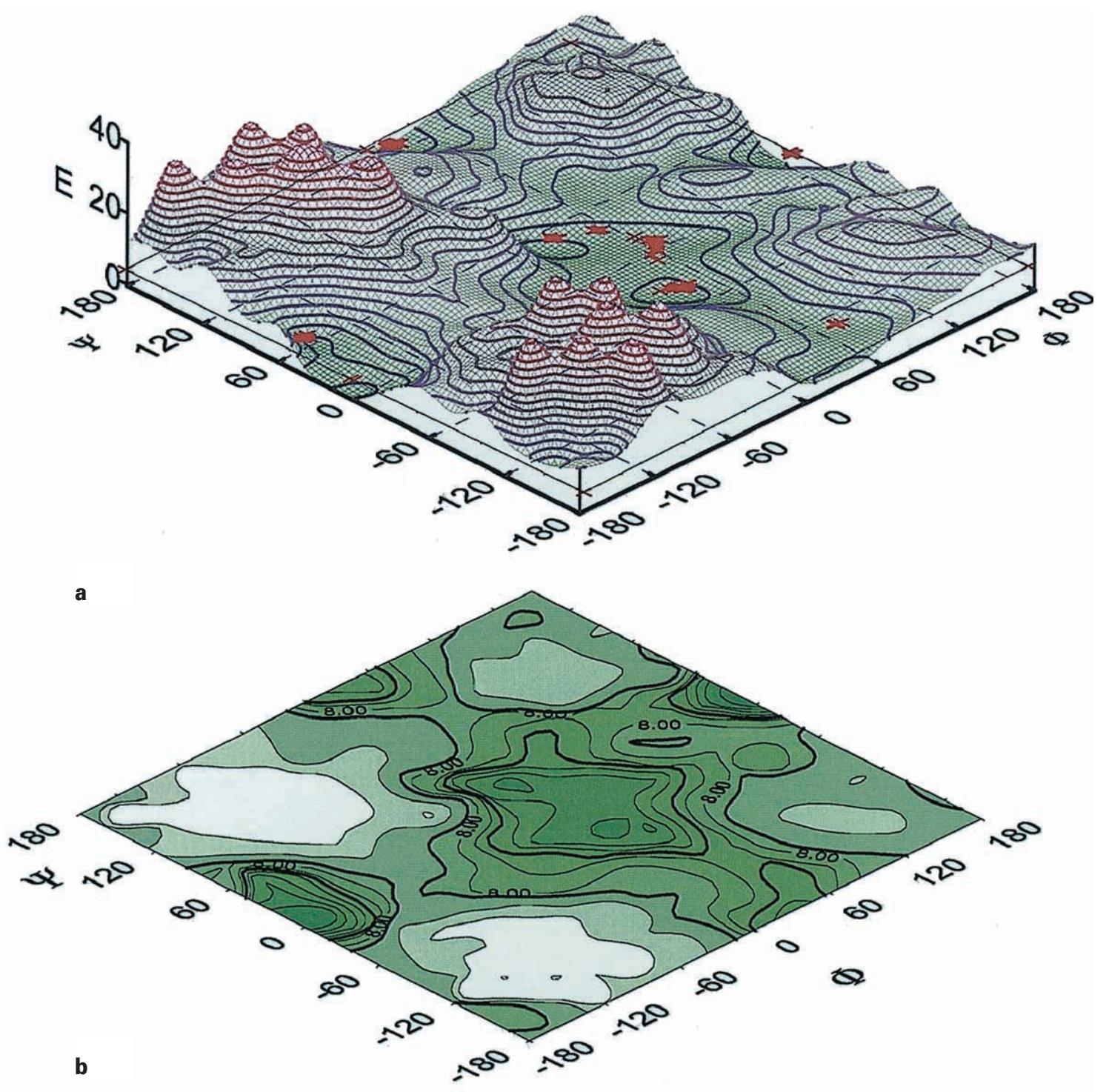

Fig. 4. Energy profile of the conformational space of the disaccharide gal- $\beta 1,2$-gal, shown in figure 3 , based on computer-assisted calculations. Comparable to topographic maps the energy levels of each $\phi, \psi$-angle combination of a systematic grid search can be shown in 3D (a) or 2D (b) representations (contour lines denote energy levels in $\mathrm{kcal} / \mathrm{mol}$ ). Low-energy positions can independently be calculated by the conformational clustering approach, indicated by red crosses in the 3D map (a).

considered as low-altitude positions. When balls are allowed to freely take their path from any starting point in the landscape, they will end up in a distinct set of positions (the equivalent of conformational clusters) after taking a suitable downhill route, as seen in figures $4 \mathrm{a}, 5 \mathrm{~d}$. Energy barriers between local minima can preclude the final movement of the balls into a - if present - global 'low-altitude position'. The decision on the starting point governs the ar- rival at the final destination. Therefore, several clusters are apparent in the 3D/2D representations (fig. 4a, 5d). Their occurrence prompts the pertinent question of what will happen when thermal energy in the biologically acceptable range is available to the molecules. Inherently, the molecular mechanics calculations will not answer the question of whether and how often an energy barrier will be crossed due to the permanent internal movements of the molecule at 


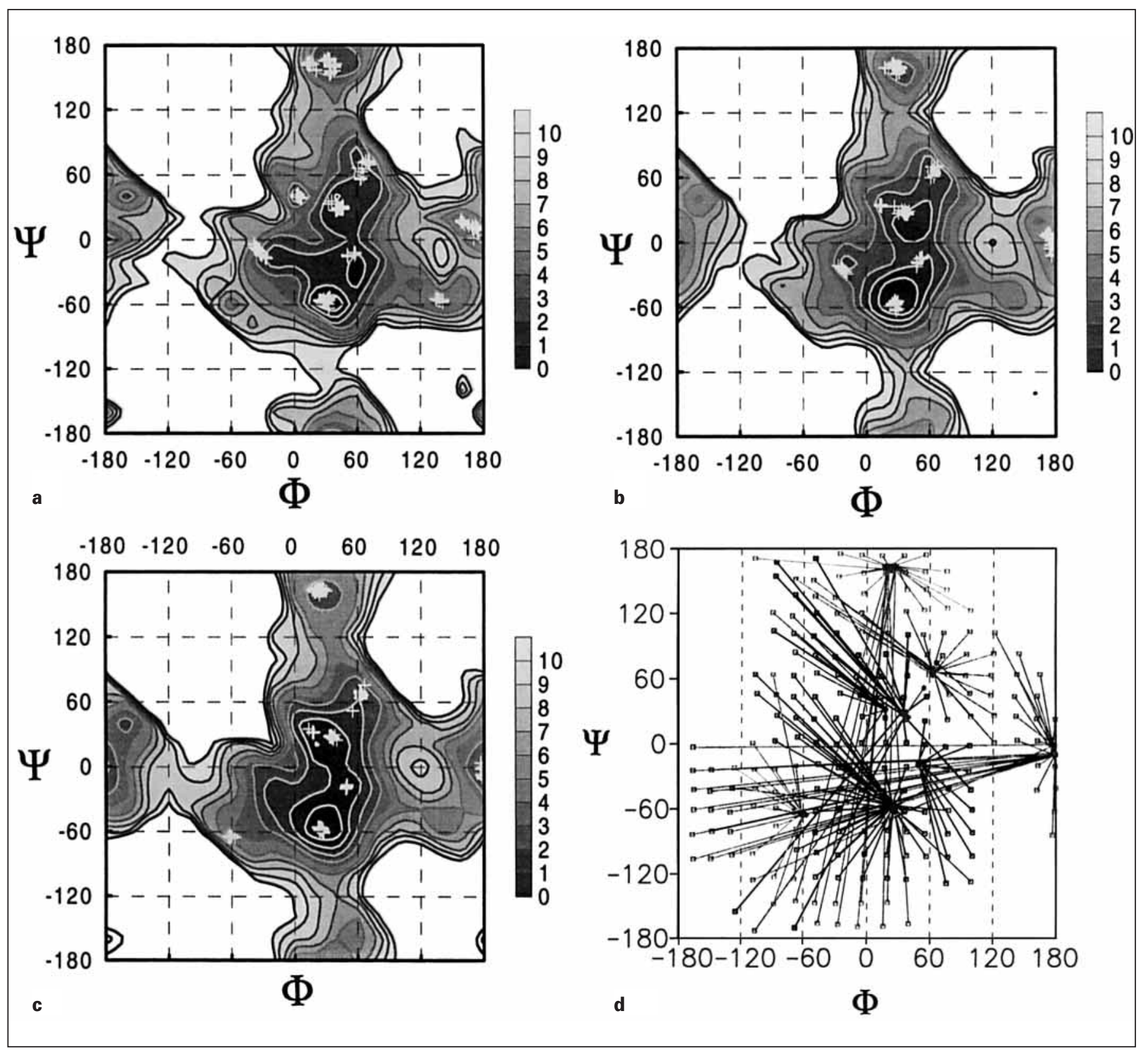

Fig. 5. Energy profile representation of the results of random walk molecular mechanics calculations (energy levels from 0 to $10 \mathrm{kcal} / \mathrm{mol}$ ) and of the conformational clustering approach (low-energy positions marked by crosses) for the disaccharide gal- $\beta 1$,3-gal with consideration of different dielectric constants $[\varepsilon=1.5$ (a), b: $\varepsilon=4$ (b), c: $\varepsilon=80$ (c)] and illustration of the results of the conformational clustering approach (low-energy positions marked by crosses) revealing the initial and final positions for this disaccharide at $\varepsilon=80(\mathbf{d})$.

$37^{\circ} \mathrm{C}$. Consideration of the factor 'time', establishing trajectories of angle fluctuations, leads to molecular dynamics calculations with the aim to describe the traffic of molecules between local energy valleys separated by barriers [von der Lieth et al., 1997b].

Conformational Behavior of Lectin Ligands
Molecular dynamics calculations describe the motional behavior of a system of atoms at a certain temperature using differential equations of motion in the context of a force field. The alterations of location by molecular motions, so-called trajectories, can be visualized as a series of 
Fig. 6. Illustration of the disaccharide gal- $\beta 1,2$-gal which is surrounded by water molecules (upper part). When the dynamic behavior of the disaccharide concerning the $\phi, \psi$-angle position is calculated for a period of 1,000 ps with explicit consideration of presence of water molecules, the disaccharide preferentially exhibits angle positions in the central low-energy valley (bottom).

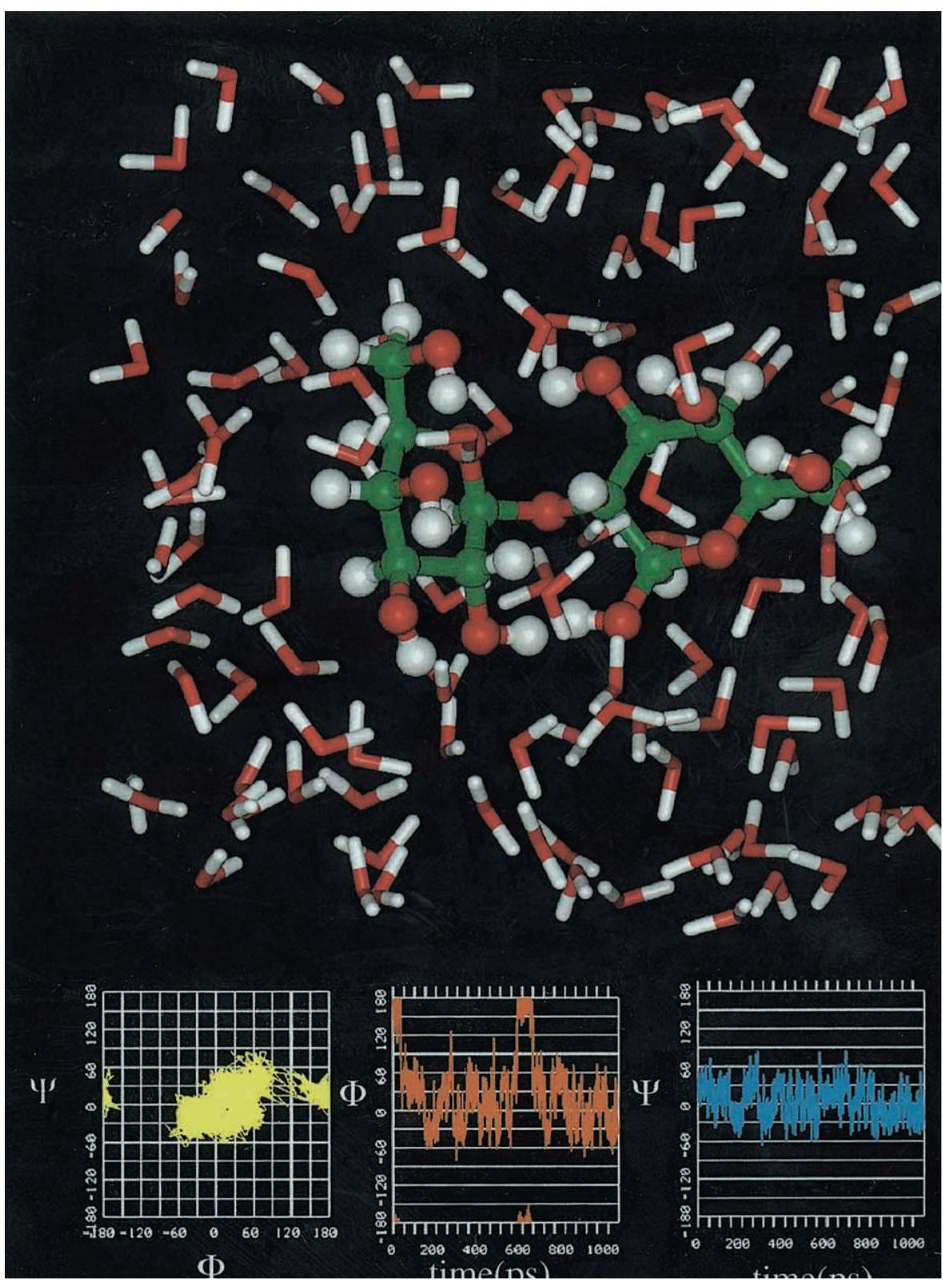

snapshots of a molecule after distinct periods of time. The selection of the length of this interval is determined by the velocity of the fastest vibrations within the molecule. To closely follow stepwise alterations of any aspect of conformation, the 'snapshot' should be recorded before e.g. one $\mathrm{C}-\mathrm{H}$ stretch vibration is completed and the next vibration is already under way. Consequently, periods of $1 \mathrm{fs}\left(10^{-15} \mathrm{~s}\right)$ are chosen to be able to establish trajectories of $\phi, \psi$-alterations. They are sufficient to account for the behavior of the molecule during the period of individual stretch vibrations which are measured to last approximately $10 \mathrm{fs}$. Examples of trajectories for the two torsion angles of a disaccharide are shown in figure 6 . They reveal the population of the two local energy minimum conformations in the central lowenergy valley owing to frequent fluctuations between the two $\psi$-positions which are marked by crosses (fig. 4a) or the topographical designations (fig. 4b). Positions of $180^{\circ} /-180^{\circ}$ for the $\psi$-angle are not populated. They are not even stable, when chosen as starting point for the molecular dynamics run. Remarkably, this calculation includes the presence of solvent molecules, which generally damp the frequency of oscillations and transitions [Kožár and von der Lieth, 
1997]. In view of biological systems with water, their consideration is essential, although the number of equations of motions automatically increases. The square of the number of atoms in the system is relevant to estimate the duration of the calculations. If the size of the calculations exceeds a reasonable computational time to complete the run, the effect of solvent molecules is approximated by choosing a certain value for the dielectric constant.

Although this procedure certainly is a simplification of the complex system established by an oligosaccharide in solution, these approximations are generally approved of, until the problem of the enormous size of calculation steps to be preferably carried out in a few hours is solved. Since this parameter change also is of relevance for molecular mechanics calculations, its impact warrants attention in this field. As evident from figure 5a-c, molecular mechanics calculations are affected quantitatively, but not qualitatively by the deliberate change of $\varepsilon$-values from 1.5 to 4.0 or 80 , underscoring the practicability of this approach. Its current necessity is emphasized by the following appendix.

Practically, simulation periods cover the range of $1 \mathrm{~ns}$. To give an idea on the required calculation time for such a run on a unix workstation for a disaccharide, it is mentioned that in the case of maltose and vacuum as simulated environment $3 \mathrm{~h}$ can be expected to complete the processing. When the disaccharide is embedded in a solvent box with 1,443 water molecules, the same workstation has to be busy full-time for $635 \mathrm{~h}$ [von der Lieth et al., 1997b].

As illustrated in figures 4 and 6 , the combination of molecular mechanics and molecular dynamics simulations provides insights into the positions of low-energy conformations in the $\phi, \psi$-map and the frequency of transitions between such conformations. Evidently, oligosaccharides cannot not superficially be referred to as rigid molecules. In contrast, the concept of the possibility for an ensemble of energetically favorable conformers as ligands is increasingly appreciated [Hardy, 1997; von der Lieth et al., 1997b; Gabius, 1998]. This knowledge has far-reaching consequences for the understanding of protein-carbohydrate interaction. Detailed calculations for any sugar compound are indispensable, because a low-energy conformer can in principle be the object of selection by a receptor. The facts that various conformational families can be discerned well and that their relative share on the total population can be constant or can vary with sequence alterations are e.g. emphasized for blood group $\mathrm{H}$ trisaccharides. Whereas the trisaccharides of $\mathrm{H}$ type 1 , type 2 and type 6 blood group epitopes preferentially take up one conformation with only a share of $3.5-5 \%$ of the total population residing in the minor conformation, $\mathrm{H}$ type 3 and type 4 trisaccharides dis- play different features [Imberty et al., 1995]. Their populations are rather equally distributed between two conformational families. Especially when low-energy conformations are positioned in different sections of a rather extended low-energy-level valley, frequent transitions between two positions separated only by a minor barrier can occur, as also recently shown for disaccharide ligands of galactosidebinding lectins [Gilleron et al., 1998]. This situation calls for answering the question about the spatial parameters of a flexible ligand after complex formation with a receptor. Before this issue will be addressed, it must not be overlooked that our reasoning on flexibility up to this point exclusively rests on computer-assisted calculations. Their results need to be ascertained by experimental input.

An indication for the inherent flexibility is given by the often noted difficulty to crystallize complex carbohydrates. Even if successful, crystallography cannot reflect the dynamic behavior of molecules in solution. Therefore, spectroscopic techniques which afford the capacity to monitor molecules in solution are essential, as already emphasized by Geyer and Geyer [1998] in this issue with respect to the structural analysis of the glycan part of glycoconjugates. In NMR spectroscopy through-space dipolar interactions between protons which act as transmitter-receiver pair, if placed in spatial vicinity (the distance is generally smaller than $3.5 \AA$ for oligosaccharides) for a finite time period, are a valuable source of information [Carver, 1993; Homans, 1995; Siebert et al., 1997b]. These contacts can be intra- and interresidual. To gather information on $\phi, \psi$-combinations, only interresidual contacts are useful, which qualify to draw conclusions on the $\phi, \psi$-features, as indicated in figure $7 \mathrm{a}, \mathrm{b}$. If a molecule is completely rigid, the measurement of these nuclear Overhauser effects (NOE) allows to unequivocally translate the signal intensities into internuclear distances, employing the spectroscopic signal as molecular ruler. For a rather rigid molecule no further complications affect the interpretation. However, the inherent flexibility with rapid fluctuations hampers such straightforward derivation of conclusions in most cases. The representation of the NMR-derived information as a single (virtual) conformation can then be misleading. It is essential to keep in mind that individual conformers will contribute to the overall signal, because the comparatively long time frame of the measurement cannot distinguish between the frequently and rapidly changing positions. The lack of ability to carry out snapshots in the ps range with the NMR spectrometer causes inevitable time- and ensemble-averaging over all contributing conformers [Jardetzky, 1980; Carver, 1991; Pearlman, 1994; Siebert et al., 1997b]. Since the number of interresidual contacts in oligosaccharides is 


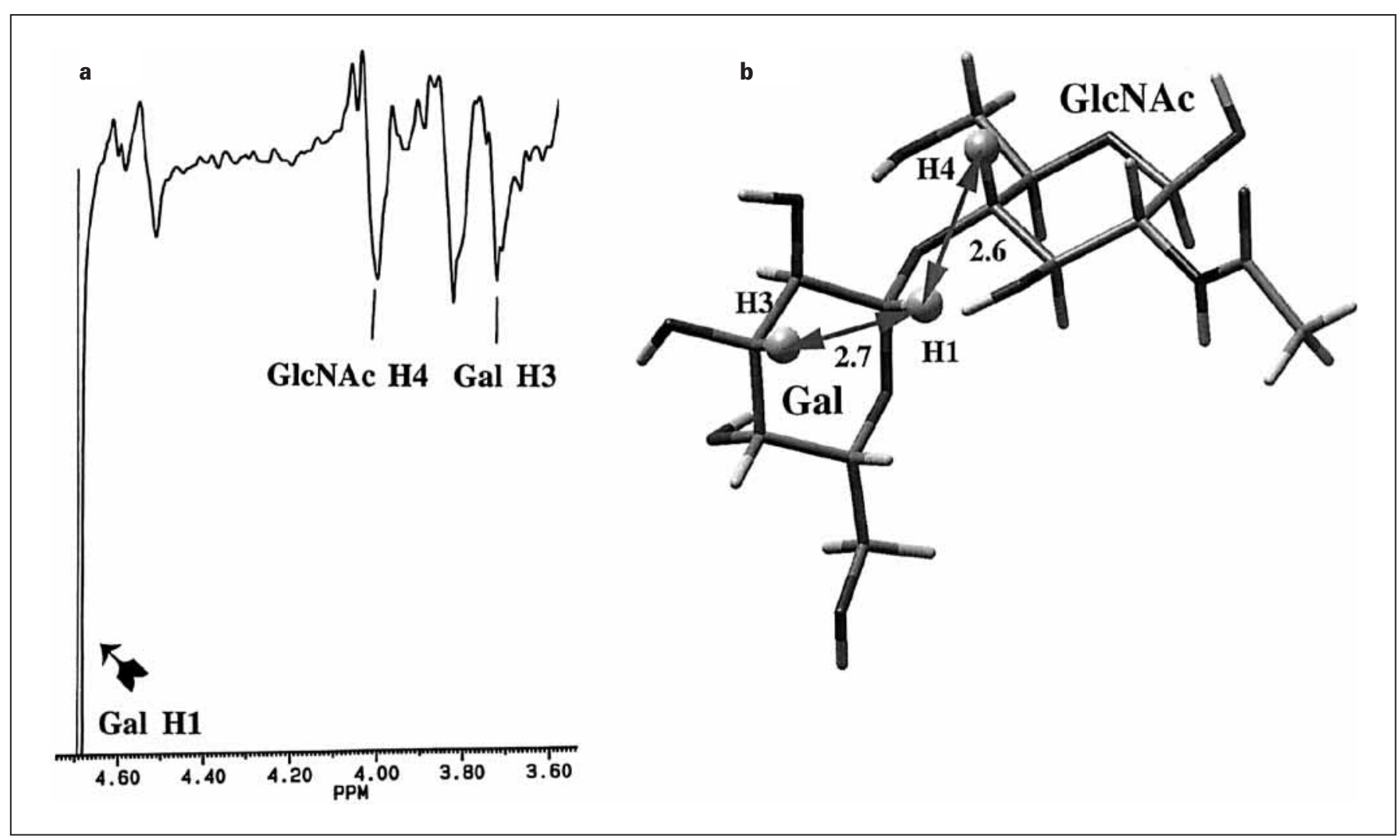

Fig. 7. Representation of a trNOE spectrum of the complex between the galactoside-specific mistletoe lectin and the disaccharide gal- $\beta 1,4$-glcNAc irradiated with the resonance frequency of the anomeric proton of the galactose moiety (Gal H1). It shows evidence for a through-space magnetization transfer to an intraresidual proton (Gal H3) and to an interresidual proton (GlcNAc H4). These signal intensities allow to calculate the average distances (in $\AA$ ) to the anomeric proton, given in $\mathbf{b}$. Any interresidual contact is relevant to delimit the accessible conformational space defined by $\phi, \psi$-combinations.

generally small, the availability of only one or few distance constraint(s) and the problem of averaging preclude a precise depiction of an actual conformation. However, at least the problem of averaging is not insurmountable.

To generate an NOE, two protons come into a dipolar contact over a fixed distance or over two or more individual distances which are averaged during the measurement. Taking flexibility into account, the probably averaged signal can originate from e.g. two distances. This assumption is the basis of the distance-mapping approach [Poppe et al., 1990; Siebert et al., 1997b; von der Lieth et al., 1997b]. The actual presence of an interresidual dipolar contact is attributed to two true distances, which yield the measurable distance upon averaging. The lower limit for the distance of $2.0 \AA$ is given by the van der Waals radii. As already indicated for carbohydrates in the preceding paragraph, an upper limit will not generally exceed $3.5 \AA$, because the strength of the through-space magnetization transfer fades away with an $\mathrm{r}^{-6}$ dependence on the distance between sender and receiver protons. Upper and lower limits encircle a section of the $\phi, \psi$-space by contour lines. This set of contour lines defines an ensemble of $\phi, \psi$-combinations which are consistent with the distance constraint(s) derived from the NMR experiment. The principal idea is drawn in figures $8 \mathrm{a}$ and $9 \mathrm{a}$. Weighting of this total population of $\phi$, $\psi$-combinations can be performed by combining the illustrations of the mapping approach with the results of molecular mechanics calculations. If a second distance constraint is available, the size of the population with compatible $\phi$, $\psi$-combinations in the area of overlap is drastically reduced, as easily apparent in figures 8a and 9a. Again, accounting of energy levels in this marked area is conducive to infer conformational parameters of a disaccharide. Thus, NMR-derived distance constraints are helpful to deduce 
whether conformational energy valleys can be populated in solution. If they do not fit into the area delimited by a set of contour lines in the distance-mapping approach, the probability for the occurrence of the corresponding $\phi, \psi$-combinations is negligible. These constraints can also be assessed experimentally for ligands associating to a receptor and rapidly exchanging between solution and the binding site. The monitoring of transferred NOE (trNOE) in receptor/ ligand mixtures at subsaturational receptor concentrations provides a means to characterize spatial features of the bound ligand [Lian et al., 1994; Ni, 1994].

\section{The Ligand's Topology in Complex with the Lectin}

A complete elucidation of the ligand's conformation in the binding pocket by NMR spectroscopy would require to collect the entire set of resonances from the complexed molecules in technically demanding multidimensional NMR techniques [Hull, 1994]. The sheer quantity of signals which must be ascribed to individual protons limits the scope of this sophisticated method to rather small proteins. It is not surprising under these circumstances that the smallest known lectin, i.e. hevein with its 43 amino acids, has so far been the prime target for this approach [Asensio et al., 1995]. Although astounding progress is currently made in this area and isotope-enriched receptors and ligands can simplify the task, the magnetization transfer between ligand protons is still sure to be a major source of topological information. trNOEs are visible as sharp negative signals in the spectrum (fig. 7). As already explained in the preceding paragraph, the intensities of intraresidual signals calibrate the distance scale and facilitate to translate peak sizes into average distances for any interresidual contact (fig. 7). However, one factor must not be disregarded to safely reach a flawless interpretation. When the ligand associates with its receptor, protons of the ligand will come into spatial vicinity of protons from amino acids establishing the binding site. Since the through-space magnetization transfer will not distinguish between protons of the ligand or receptor, protein protons can indirectly be involved in this process as mediators to let ligand protons communicate [Arepalli et al., 1995; Peters and Pinto, 1996; Siebert et al., 1997b]. This process is graphically denoted as spin diffusion. Adequate technical procedures have already been suggested to eliminate the possibility to be led astray, e.g. short mixing times at low ligand concentrations or monitoring in the rotating frame under spin-locking conditions. The protocols ensure the validity of trNOE-derived conclusions.
The technique to measure magnetization transfer of a ligand's proton in the presence of the receptor thus invites the exploration of the question of whether individual conformers of an oligosaccharide can be selected by distinct receptors. Recalling the presentation of the dynamic properties of the disaccharide gal- $\beta 1,2$-gal in figure 6 , it has been tempting to analyze lectin/ligand complexes to reveal whether conformer selection is actually operative for different types of lectin. In that case, cell biologists and histochemists can rightfully glean the take-home message from such experiments that besides the sequence the conformation of the lectin ligand must be clarified to comprehend the details of the recognitive interplay.

Independent origins of binding sites can make it likely that their architectures will differ. Since the disaccharide under scrutiny is known to bind to plant and animal lectins [Lee et al., 1992, 1994; Siebert et al., 1996], monitoring of trNOE for the galactoside-binding lectins from a plant (Viscum album L.) and an animal (chicken liver galectin) was instrumental to answer this question [Siebert et al., 1996; Gilleron et al., 1998]. As shown in figures 8 and 9, the concept of differential conformer selection by the two lectins with the same nominal specificity to $D$-galactose was verified. In complete agreement with the results of the computer calculations, experimental evidence for the presence of the two predicted conformations for the free ligand in solution was provided by NMR spectroscopy (fig. 10). Two of the three interresidual contacts which are visible for the free ligand are characteristic for the two different complexes (see schematic depiction of the two contacts in the right parts of fig. 8 and 9, respectively, relative to fig. 10). Notably, no marked alteration in the conformation of the ligand appeared to take place upon binding of the chosen conformer. This conclusion is reinforced by a recent documentation that the three selectins (E- and P-selectin vs. Lselectin) also use conformer selection in ligand recognition [Poppe et al., 1997]. Thus, a snugly and thermodynamically favorable fit of substantial portions of the ligand into a binding site is feasible from various positions of a lowenergy valley. With curiosity this result is set into relation to the information from crystallography.

Unfortunately, these proteins have so far not been analyzed as complexes in crystals, which only permits a general comparison including mentioning of two potential shortcomings of this technique. Although the aim of crystallization often calls for nonphysiological conditions to favor crystal initiation and growth, and although the packaging in the rigid crystal structure may distort sensitive conformational features of the solution structure, it is reassuring to note that similar observations on the selection of 


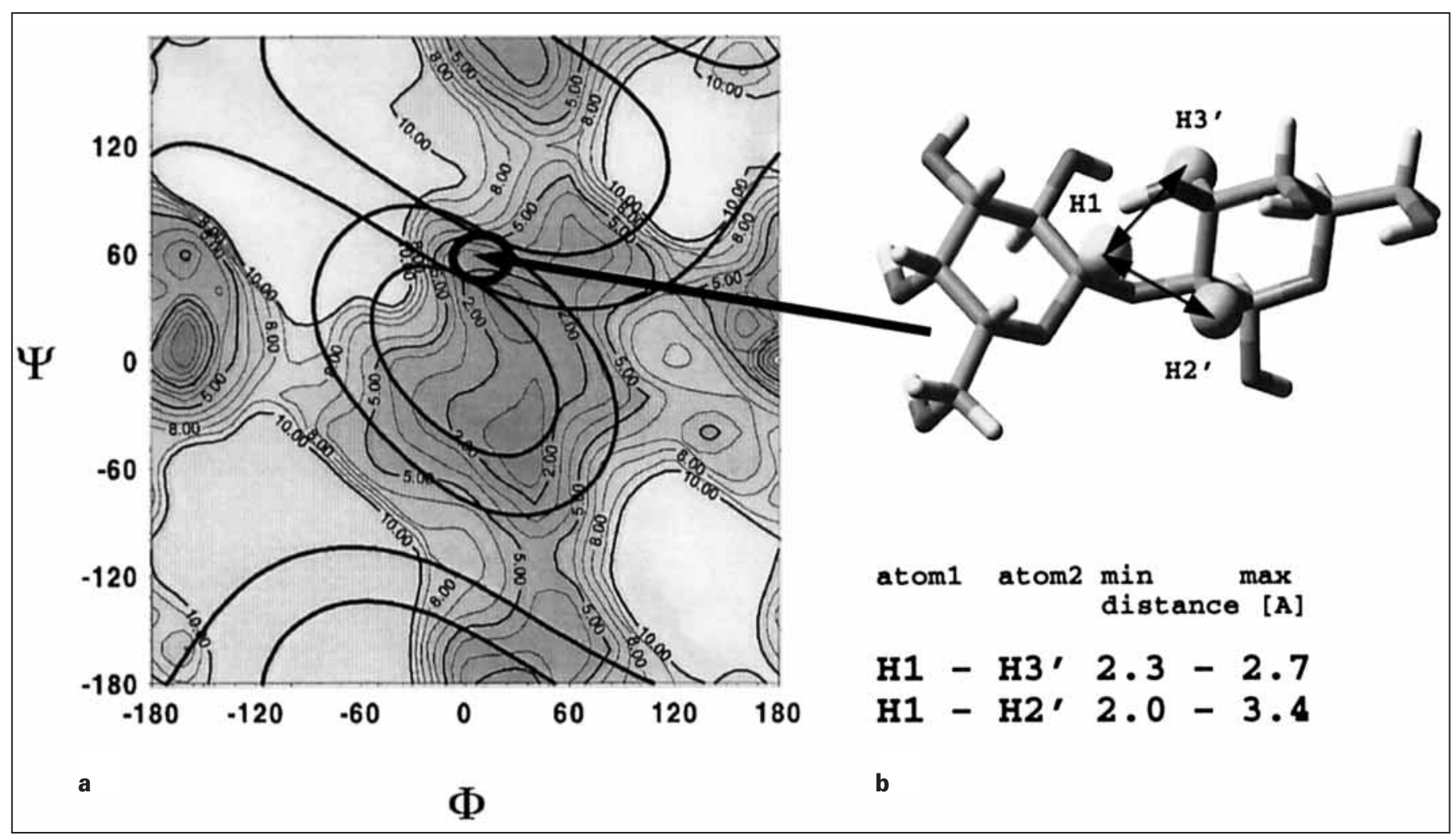

Fig. 8. Derivation of an example for a probable lectin-bound conformation of the disaccharide gal- $\beta 1,2$-gal in the complex with the galactose-specific mistletoe lectin (b) by plotting distance constraints of the two interresidual trNOE contacts into the $2 \mathrm{D}$ representation of the energetic levels of $\phi, \psi$-angle combinations (a). The area of overlap of the two contour line sets obtained from the two indicated through-space contacts (see arrows, b) defines the conformational space which is accessible to the bound ligand. A resulting conformation is drawn and its position in the plot is marked.

low-energy conformers have been made for several crystallized lectin/ligand complexes [Sharon, 1993; Cambillau, 1995; Rini, 1995; Weis and Drickamer, 1996; Elgavish and Shaanan, 1997; Gabius, 1997a, 1998]. However, a binding pocket of a sugar receptor can also be capable of imposing an induced fit on the ligand, documented for the antigenic determinant of a Salmonella lipopolysaccharide and the glcNAc- $\beta 1$, 2-man torsion angle in a concanavalin A-binding pentasaccharide [Bundle, 1997; Moothoo and Naismith, 1998]. The acquired knowledge about the topological details of the ligand is not only of purely academic interest, satisfying scientific curiosity. Aiming at medical progress, custom-made tailoring of ligand features with respect to the receptor is guided by this information. When musing on how to achieve advances in the design of ligand analogs, the topological information gained by NMR experiments is conducive. In addition to blocking antibodies or lectins optimized ligands as oligosaccharides or glycomimetics may eventually find applications as clinically beneficial thera- peutics in antiadhesion therapy to fight viral or bacterial infections, undesired inflammation or tumor spread, as illustrated in figure 11, or as targeting device in organ/cell type-selective drug delivery [Gabius, 1988, 1997b, 1998; Karlsson, 1991; Colman, 1994; Grootenhuis et al., 1994; Gabius et al., 1995, 1996; Simon, 1996; Zopf and Roth, 1996; Cornejo et al., 1997; Lowe and Ward, 1997; Mahal and Bertozzi, 1997; Rice, 1997; Witczak, 1997].

Automatically, this clinical perspective prompts the question of how to achieve an optimal rational drug design. Ligand and receptor properties will have to be exploited on the way towards this aim. Besides the description of the bound conformation the topology of the binding site can be mapped with chemically engineered ligand analogs, as carried out for the mistletoe lectin and galectins [Lee et al., 1992; Solís et al., 1994, 1996; Diaz-Mauriño and Solís, 1997]. If crystals of any member of a protein family have already been analyzed, salutary information can be gleaned from their diffraction pattern for knowledge-based homology modeling. 


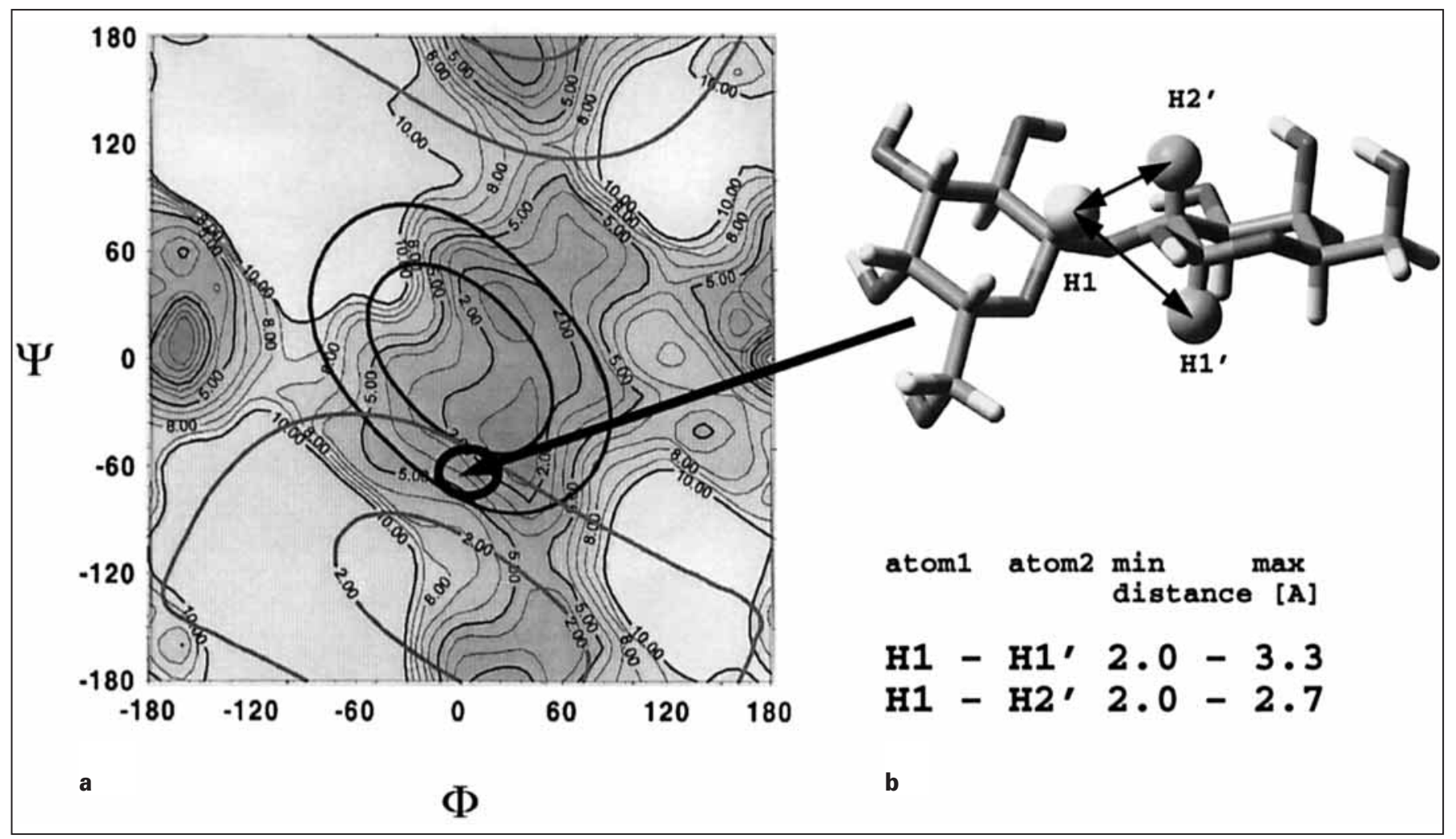

Fig. 9. Derivation of an example for a probable lectin-bound conformation of the same disaccharide, as given in figure 8 , in the complex with the avian galectin from chicken liver (CG-16). The measured distance constraints point to a position of the bound ligand in the energy map (a) which is different from that one, shown in figure 8 for the case of the mistletoe lectin. Consequently, the galectin selects a different conformer from the central low-energy valley for binding (b).

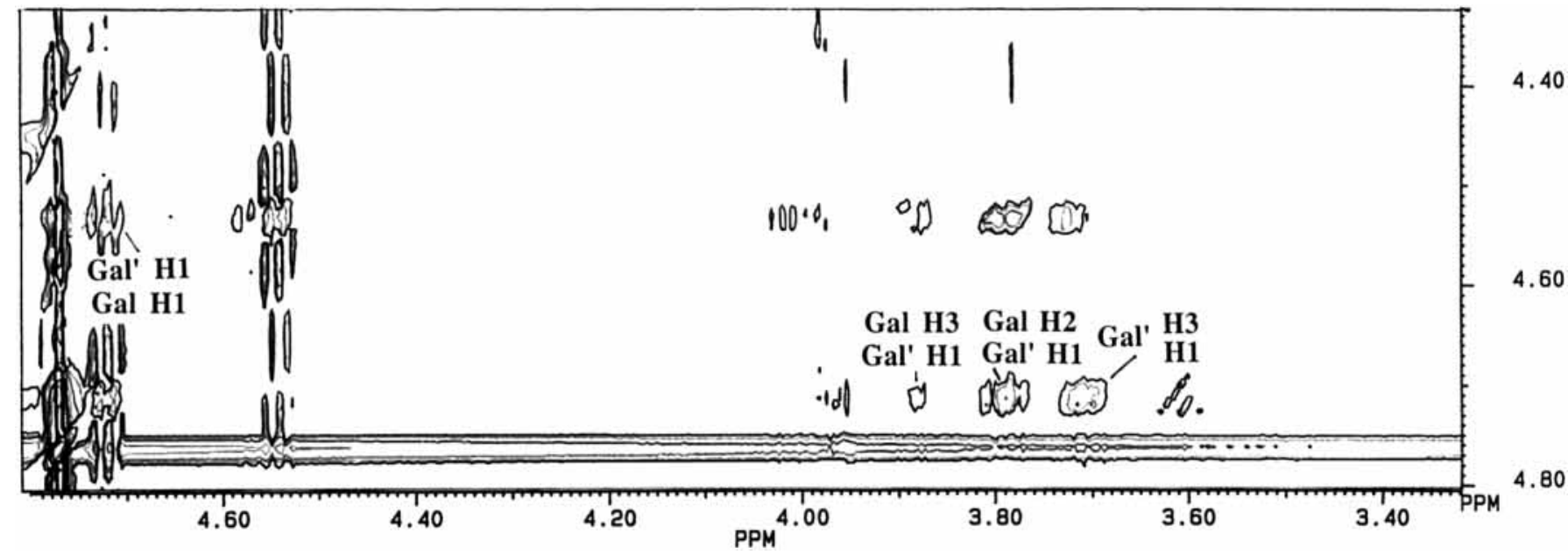

Fig. 10. Relevant part of a $2 D$ ROESY spectrum of free gal'- $\beta 1,2$-gal $\beta 1-R$ in solution with cross-peaks indicative of three interresidual contacts. They are reconcilable with the two independent conformations, shown in figures 8 and 9. 
Fig. 11. Therapeutic strategies to interfere with lectin-mediated cell adhesion by application of blocking reagents, i.e. lectinspecific antibodies, a ligand-occupying soluble lectin and an excess of tailor-made oligosaccharides or glycomimetics which saturate ligand-binding sites.
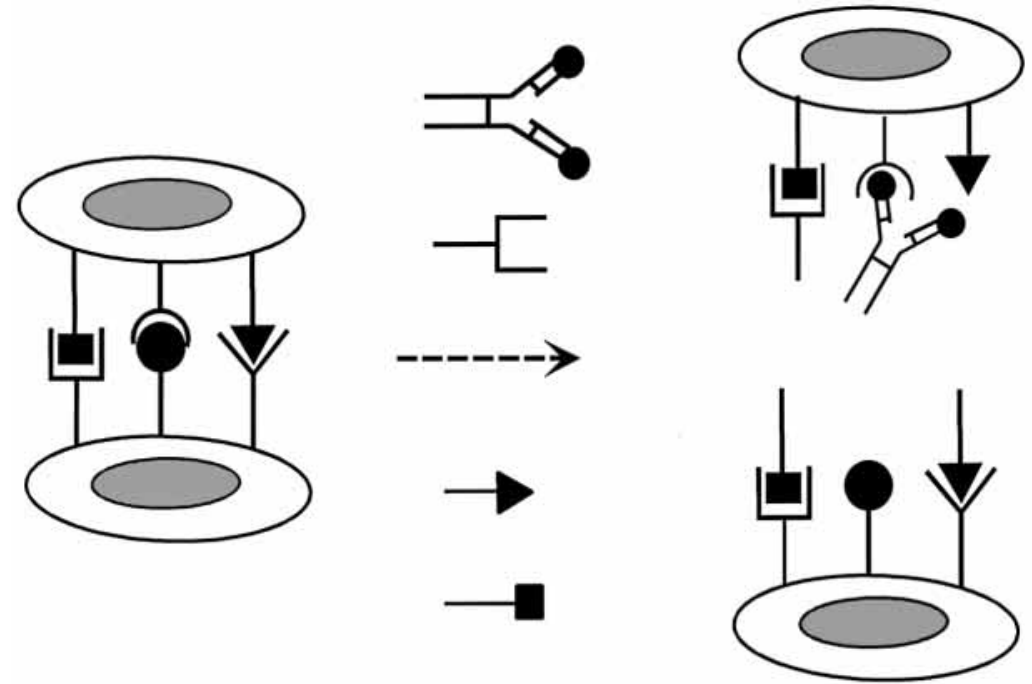

\section{Knowledge-Based Homology Modeling: The Harmonious Marriage between Theoretical Concepts and Experimental Input}

The exploitation of knowledge about the binding site architecture and the structure of the bound ligand has already matured to clinical trials in several instances [Colman, 1994; von Itzstein and Colman, 1996; Jackson, 1997; Hubbard, 1997; Marrone et al., 1997; Gabius, 1998]. Having thus explored and appreciated the potential for clinical benefit of this combined approach, which is guided by the complementarity of the techniques of crystallography and NMR with their inherently strong and weak aspects [Wagner et al., 1992; MacArthur et al., 1994], it is desirable to extend the range of target molecules by computational techniques. It is not preposterous to refer to the contributions of computations as an ongoing revolution in the field of drug design, meeting the challenge for developing new and effective lead structures [Marrone et al., 1997]. As outlined in figure 12 for a bovine galectin, the crystal structure of one member of the family provides the essential insight into the protein's folding pattern and the intimate interactions between lectin and ligand [Bourne et al., 1994]. This data set is the input for homology computations for other related proteins, e.g. a human galectin, shown in figure 12, or chicken galectins [Solís et al., 1996; Siebert et al., 1997a]. This approach has similarly been employed to generate a view of the architecture of the complex between selectins and their ligands [Weis and Drickamer, 1996; von der
Lieth, 1997]. Surely, it harbors general applicability [Johnson et al., 1994; Sowdhamini et al., 1994].

To refine the accuracy of modeling, further experimental input on conformational features of the modeled protein in solution is definitely welcome. Sensitive spectroscopic methods focusing on distinct structural aspects are helpful candidates to supplement the computational data material. Measuring the surface accessibility of tyrosine, tryptophan, and histidine residues by interaction with a laser-excitable dye, the laser photochemically induced dynamic nuclear polarization (CIDNP) technique has been applied to various plant and animal lectins [Siebert et al., 1997a, c]. Unless the

Fig. 12. Representations of the secondary structure of the prototype galectin-1 from bovine heart with the carbohydrate-binding sites, indicated by ligand occupation, at opposing ends of the noncovalently linked homodimer which displays a jelly-roll motif (top) and of the architecture of one binding site, revealing an intricate network of hydrogen bonds between ligand and receptor donor-acceptor pairs [from Bourne et al., 1994; middle part, left]. Homology-based modeling with human galectin-1, introducing its known substitutions relative to bovine galectin, results in an illustration of the binding site based on the computer calculations and the X-ray data for the bovine protein (middle part, right). Homology-based modeling using the structural parameters obtained by X-ray crystallographic analysis of bovine galectin- 1 and the experimental input by the laser photo CIDNP technique leads to structural depictions of one subunit of human galectin1 (right) and an avian galectin (CG-16, see fig.9) with the center of gravity of the ligand depicted as dot (bottom). 

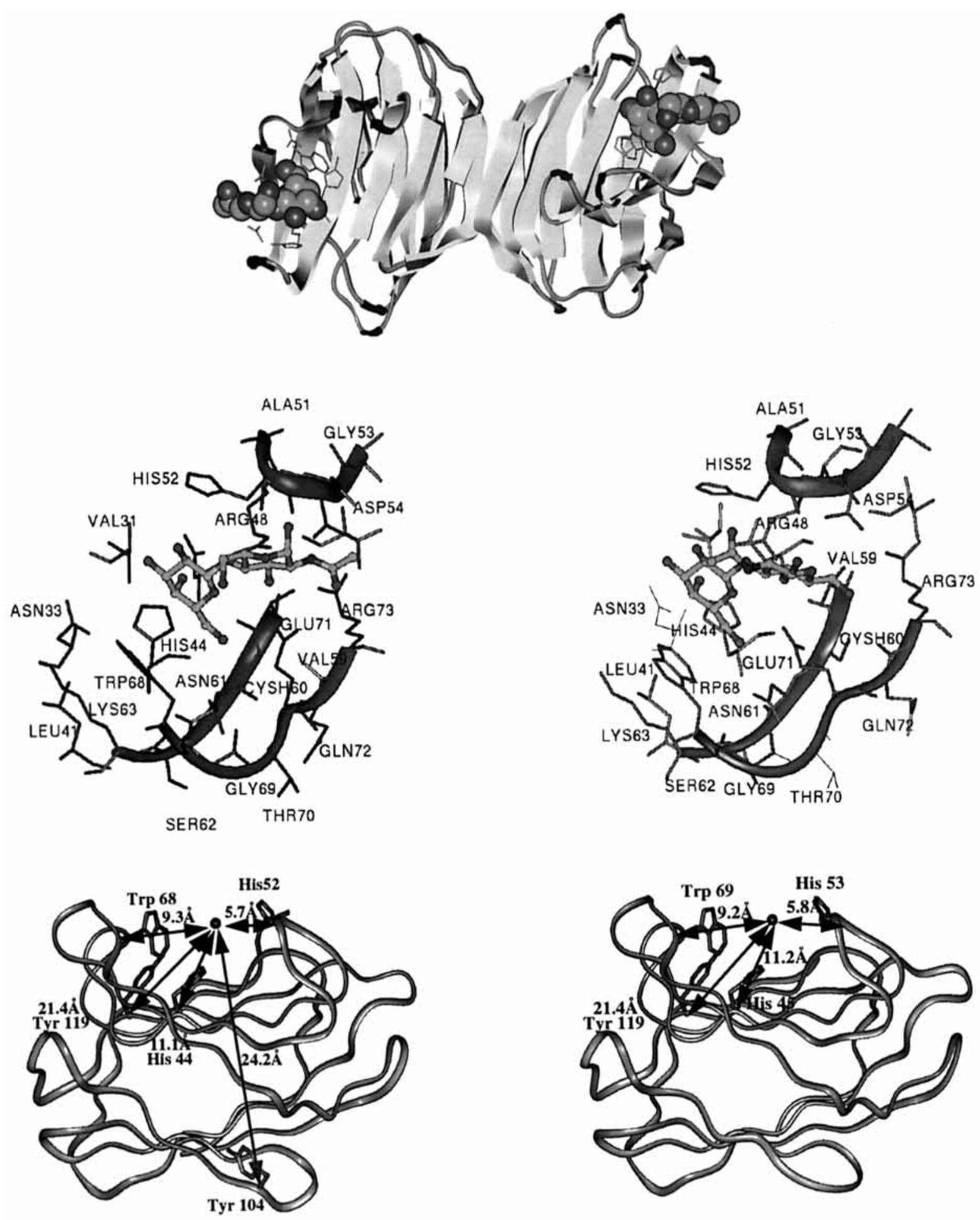
spectra are too difficult to be interpreted unambiguously owing to massive signal overlapping, this method is suitable to control and refine the reliability of modeling with respect to the determined parameters. When the laser-excitable dye is replaced by a fluorophore, the transfer of fluorescence energy can be quantified in solution. In analogy to transfer of magnetization the actual distance between sender and receiver is manifested in signal intensity [Lee, 1997]. Unlike the measurement of NOE, which is restricted to short distances due to the $\mathrm{r}^{-6}$ dependence of the dipolar interaction, fluorescence energy transfer is a 'molecular ruler' in the distance range of 5-100 $\AA$ [Stryer, 1978]. Further evidence for side chain positioning on the surface or in the binding site can be gathered by chemical methods such as modification by target-selective reagents or (photo-)cross-linking to group-specific probes. Elaboration of the algorithms in modeling of proteins prior to and after docking of the ligand will continuously be improved by the input of empirical information.

\section{Conclusion}

When the problems of identifying and localizing a certain receptor activity in a cell and of monitoring its spatial and temporal expression pattern are to be solved, a ligand is a prime candidate as tool. Only immobilization to a histochemically inert carrier backbone is required to yield a histochemical marker. Unless the receptor's activity is blocked or impaired by tissue processing and the ligand's interaction potential is diminished by derivation, such 'neoligando- conjugates' can find a broad range of applications [Gabius and Bardosi, 1991; Kayser et al., 1991; Danguy et al., 1995; Kayser and Gabius, 1997]. Focusing on glycobiology, the feasibility of chemical design of neoglycoconjugates has already engendered considerable efforts [Lee and Lee, 1994]. They have enabled to accrue complementary information to conventional lectin histochemistry by the exploitation of neoglycoconjugates, termed 'reverse lectin histochemistry' [Gabius et al., 1993; Danguy et al., 1994, 1995]. In view of the ample documentation of lectin expression in animal tissues, to which this technique contributes remarkably, it is no longer appropriate to consider the area of lectinology as a bashful search for any tenuous thread of evidence for a physiological relevance. On the contrary, the concept of the sugar code is well established and the emphasis of research has shifted from detection to delineation of structural and functional details of lectin-carbohydrate interactions and their elicited signaling processes [Mandal and Brewer, 1993; Gabius, 1997a, b; Villalobo and Gabius, 1998]. Such investigations have uncovered a veritable degree of conformational flexibility of ligands and are currently unraveling intimate details about their molecular rendez-vous with a lectin. Combinations of NMR spectroscopy and X-ray crystallography with sophisticated computer calculations encompassing molecular mechanics, molecular dynamics, homology modeling and docking algorithms are pertinent to comprehend how the sugar language is decoded. Moving forward from this firm foundation, it is reasonable to expect proper guidance from this panel of methods on the way to an optimized rational marker or drug design with clinical implications.

\section{References}

André, S., C. Unverzagt, S. Kojima, X. Dong, C. Fink, K. Kayser, H.-J. Gabius (1997) Neoglycoproteins with the synthetic complex biantennary nonasaccharide or its $\alpha 2,3-/ \alpha 2,6$ sialylated derivatives: Their preparation, the assessment of their ligand properties for purified lectins, for tumor cells in vitro and in tissue sections and their biodistribution in tumorbearing mice. Bioconjug Chem 8: 845-855.

Arepalli, S.R., C.P.J. Glaudemans, G.D. Daves, P. Kovac, A. Bax (1995) Identification of proteinmediated indirect NOE effects in a disaccharide-Fab' complex by transferred ROESY. J Magn Reson B 106: 195-198.
Asensio, J.L., F.J. Cañada, M. Bruix, A. Rodriguez-Romero, J. Jimenez-Barbero (1995) The interaction of hevein with $\mathrm{N}$-acetylglucosamine-containing oligosaccharides. Solution structure of hevein complexed with chitobiose. Eur J Biochem 230: 621-633.

Ashwell, G., J. Harford (1982) Carbohydrate-specific receptors of the liver. Annu Rev Biochem 51: 531-554.

Barondes, S.H. (1984) Soluble lectins: A new class of extracellular proteins. Science 223: 1259-1264.

Bourillon, R., M. Aubery (1989) Cell surface glycoproteins in embryonic development. Int Rev Cytol 116: 257-338.
Bourne, Y., B. Bolgiano, D. Liao, G. Strecker, P. Contau, O. Herzberg, T. Feizi, C. Cambillau (1994) Crosslinking of mammalian lectin, galectin-1, by complex biantennary saccharides. Nat Struct Biol 1: 863-870.

Bovin, N.V., H.-J. Gabius (1995) Polymer-immobilized carbohydrate ligands: Versatile chemical tools for biochemistry and medical sciences. Chem Soc Rev 24: 413-421.

Brinck, U., M. Korabiowska, R. Bosbach, H.-J. Gabius (1998) Detection of inflammationand neoplasia-associated alterations in human large intestine by plant/invertebrate lectins, galectin-1 and neoglycoproteins. Acta Anat 161: 219-233. 
Brockhausen, I., H. Schachter (1997) Glycosyltransferases involved in $\mathrm{N}$ - and O-glycan biosynthesis; in Gabius H-J, S Gabius (eds): Glycosciences: Status and Perspectives. London, Chapman \& Hall, pp 79-113.

Brockhausen, I., J. Schutzbach, W. Kuhns (1998) Glycoproteins and their relationship to human disease. Acta Anat 161: 36-78.

Bundle, D.R. (1997) Antibody-oligosaccharide interactions determined by crystallography; in Gabius H-J, S Gabius (eds): Glycosciences: Status and Perspectives. London, Chapman \& Hall, pp 311-331.

Cambillau, C. (1995) 3D structure. 1. The structural features of protein-carbohydrate interactions revealed by X-ray crystallography; in Montreuil J, JFG Vliegenthart, H Schachter (eds): Glycoproteins. Amsterdam, Elsevier, pp 29-65.

Carver, J.P. (1991) Experimental structure determination of oligosaccharides. Curr Opin Struct Biol 1: 716-720.

Carver, J.P. (1993) Oligosaccharides: How can flexible molecules act as signals? Pure Appl Chem 65: 763-770.

Colman, P.M. (1994) Structure-based drug design. Curr Opin Struct Biol 4: 868-874.

Cook, G.M.W. (1986) Cell surface carbohydrates: Molecules in search of a function? J Cell Sci Suppl 4: 45-70.

Cook, G.M.W. (1995) Glycobiology of the cell surface: The emergence of sugars as an important feature of the cell periphery. Glycobiology 5: 449-461.

Cornejo, C.J., R.K. Winn, J.M. Harlan (1997) Antiadhesion therapy. Adv Pharmacol 39: 99-142.

Cummings, R.D. (1997) Lectins as tools for glycoconjugate purification and characterization; in Gabius H-J, S Gabius (eds): Glycosciences: Status and Perspectives. London, Chapman \& Hall, pp 191-199.

Danguy, A. (1995) Perspectives in modern glycohistochemistry. Eur J Histochem 39: 5-14.

Danguy, A., F. Akif, B. Pajak, H.-J. Gabius (1994) Contribution of carbohydrate histochemistry to glycobiology. Histol Histopathol 9: 155-171.

Danguy, A., C. Decaestecker, F. Genten, I. Salmon, R. Kiss (1998) Application of lectins and neoglycoconjugates in histology and pathology. Acta Anat 161: 206-218.

Danguy, A., K. Kayser, N.V. Bovin, H.-J. Gabius (1995) The relevance of neoglycoconjugates for histology and pathology. Trends Glycosci Glycotechnol 7: 261-275.

Diaz-Mauriño, T., D. Solís (1997) Analysis of protein-carbohydrate interaction using engineered ligands; in Gabius H-J, S Gabius (eds): Glycosciences: Status and Perspectives. London, Chapman \& Hall, pp 345-354.

Elgavish, S., B. Shaanan (1997) Lectin-carbohydrate interactions: Different folds, common recognition principles. Trends Biochem Sci 22: 462-467.

Etzler, M.E. (1985) Plant lectins: Molecular and biological aspects. Annu Rev Plant Physiol 36: 209-234.
Feizi, T., R.A. Childs (1987) Carbohydrates as antigenic determinants of glycoproteins. Biochem J 245: 1-11.

Gabius, H.-J. (1987) Vertebrate lectins and their possible roles in fertilization, development and tumor biology. In Vivo 1: 75-84.

Gabius, H.-J. (1988) Tumor lectinology: At the intersection of carbohydrate chemistry, biochemistry, cell biology and oncology. Angew Chem Int Ed 27: 1267-1276.

Gabius, H.-J. (1991) Detection and functions of mammalian lectins - With emphasis on membrane lectins. Biochim Biophys Acta 1071: $1-18$.

Gabius, H.-J. (1994) Non-carbohydrate binding partners/domains of animal lectins. Int J Biochem 26: 469-477.

Gabius, H.-J. (1997a) Animal lectins. Eur J Biochem 243: 543-576.

Gabius, H.-J. (1997b) Concepts of tumor lectinology. Cancer Invest 15: 454-464.

Gabius, H.-J. (1998) The how and why of proteincarbohydrate interaction: A primer to the theoretical concept and a guide to application in drug design. Pharm Res 15: 23-30.

Gabius, H.-J., A. Bardosi (1991) Neoglycoproteins as tools in glycohistochemistry. Prog Histochem Cytochem 22/3: 1-66.

Gabius, H.-J., S. Gabius (eds) (1993) Lectins and Glycobiology. Berlin, Springer

Gabius, H.-J., S. Gabius, T.V. Zemlyanukhina, N.V. Bovin, U. Brinck, A. Danguy, S.S. Joshi, K. Kayser, J. Schottelius, F. Sinowatz, L.F. Tietze, F. Vidal-Vanaclocha, J.-P. Zanetta (1993) Reverse lectin histochemistry: Design and application of glycoligands for detection of cell and tissue lectins. Histol Histopathol 8: 369-383.

Gabius, H.-J., K. Kayser, S. Gabius (1995) ProteinZucker-Erkennung. Grundlagen und medizinische Anwendung am Beispiel der Tumorlektinologie. Naturwissenschaften 82: 533-543.

Gabius, S., K. Kayser, N.V. Bovin, N. Yamazaki, S. Kojima, H. Kaltner, H.-J. Gabius (1996) Endogenous lectins and neoglycoconjugates: A sweet approach to tumor diagnosis and targeted drug delivery. Eur J Pharm Biopharm 42: 250-261.

Gahmberg, C.G., M. Tolvanen (1996) Why mammalian cell surface proteins are glycoproteins. Trends Biochem Sci 21: 308-311.

Galanina, O.E., H. Kaltner, L.S. Khraltsova, N.V. Bovin, H.-J. Gabius (1997) Further refinement of the description of the ligand-binding characteristics for the galactoside-binding mistletoe lectin, a plant agglutinin with immunomodulatory potency. J Mol Recognit 10: 139-147.

Geyer, H., R. Geyer (1998) Strategies for glycoconjugate analysis. Acta Anat 161: 18-35.
Gilleron, M., H.-C. Siebert, H. Kaltner, C.-W von der Lieth, T. Kozár, K.M. Halkes, E.Y. Korchagina, N.V. Bovin, H.-J. Gabius, J.F.G. Vliegenthart (1998) Conformer selection and differential restriction of ligand mobility by a plant lectin. Conformational behavior of Gal $\beta 1-3$ GlcNAc $\beta 1-R, \quad$ Gal $\beta 1-3 G a l N A c \beta 1-R$ and Gal $\beta 1-2 \mathrm{Gal} \beta 1-\mathrm{R}^{\prime}$ in the free state and complexed with mistletoe lectin as revealed by random walk and conformational clustering molecular mechanics calculations, molecular dynamics simulations and nuclear Overhauser experiments. Eur J Biochem 252: 416-427.

Grootenhuis, P.D.J., C.A.A. van Boeckel, C.A.G. Haasnoot (1994) Carbohydrates and drug discovery - The role of computer simulation. Trends Biotechnol 12: 9-14.

Hakomori, S. (1989) Aberrant glycosylation in tumors and tumor-associated carbohydrate antigens. Adv Cancer Res 52: 257-331.

Hakomori, S. (1998) Cancer-associated glycosphingolipid antigens: Their structure, organization and function. Acta Anat 161: 79-90.

Hardy, B.J. (1997) The glycosidic linkage flexibility and time-scale similarity hypotheses. J Mol Struct 395/396: 187-200.

Homans, S.W. (1995) 3D structure. 2. Threedimensional structures of oligosaccharides explored by NMR and computer calculations; in Montreuil J, JFG Vliegenthart, H Schachter (eds): Glycoproteins. Amsterdam, Elsevier, pp 67-86.

Hooper, L.V., S.M. Manzella, J.U. Baenziger (1997) The biology of sulfated oligosaccharides; in Gabius H-J, S Gabius (eds): Glycosciences: Status and Perspectives. London, Chapman \& Hall, pp 261-276.

Hounsell, E.F. (1997) Methods of glycoconjugate analysis; in Gabius H-J, S Gabius (eds): Glycosciences: Status and Perspectives. London, Chapman \& Hall, pp 15-29.

Hubbard, R.E. (1997) Can drugs be designed? Curr Opin Biotechnol 8: 696-700.

Hull, W.E. (1994) Experimental aspects of twodimensional NMR; in Croasmun WR, RMK Carlson (eds): Two-Dimensional NMR-Spectroscopy: Applications for Chemists and Biochemists. New York, VCH Publishers, pp 67-456.

Imberty, A. (1997) Oligosaccharide structures: Theories versus experiment. Curr Opin Struct Biol 7: 617-623.

Imberty, A., E. Mikros, J. Koca, R. Mollicone, R. Oriol, S. Pérez (1995) Computer simulation of histo-blood group oligosaccharides: Energy maps of all constituting disaccharides and potential energy surfaces of $14 \mathrm{ABH}$ and Lewis carbohydrate antigens. Glycoconj J 12: 331-349.

Jackson, R.C. (1997) Contributions of protein structure-based drug design to cancer chemotherapy. Semin Oncol 24: 164-172.

Jardetzky, O. (1980) On the nature of molecular conformations inferred from high-resolution NMR. Biochim Biophys Acta 621: 227-232.

Johnson, M.S., N. Srinivasan, R. Sowdhamini, T.L. Blundell (1994) Knowledge-based proteinmodeling. Crit Rev Biochem Mol Biol 29 . $1-68$ 
Kaltner, H., B. Stierstorfer (1998) Animal lectins as cell adhesion molecules. Acta Anat 161: 162-179.

Kannan, S., M.K. Nair (1997) Lectins and neoglycoproteins in histopathology; in Gabius H-J, S Gabius (eds): Glycosciences: Status and Perspectives. London, Chapman \& Hall, pp 563-583.

Karlsson, K.-A. (1991) Glycobiology: A growing field for drug design. Trends Pharmacol Sci 12: 265-272.

Kayser, K., H.-J. Gabius (1997) Graph theory and the entropy concept in histochemistry. Theoretical considerations, application in histopathology and the combination with receptor-specific approaches. Prog Histochem Cytochem 32/2: 1-106.

Kayser, K., H.-J. Gabius, S. Gabius (1991) Biotinylated ligands as markers for receptorbinding sites. An alternative for immunohistochemistry. Zentralbl Pathol 137: 473-478.

Kocourek, J. (1986) Historical background; in Liener IE, N Sharon, IJ Goldstein (eds): The Lectins: Properties, Functions and Applications in Biology and Medicine. New York, Academic Press, pp 1-32.

Kopitz, J. (1997) Glycolipids: Structure and function; in Gabius H-J, S Gabius (eds): Glycosciences: Status and Perspectives. London, Chapman \& Hall, pp 163-189.

Kožár, T., C.-W. von der Lieth (1997) Efficient modeling protocols for oligosaccharides: From vacuum to solvent. Glycoconj J 14: 925-933.

Kožár, T., F. Petrak, Z. Galova, I. Tvaroska (1990) RAMM - A new procedure for theoretical conformational analysis of carbohydrates. Carbohydr Res 204: 27-36.

Kresse, H. (1997) Proteoglycans: Structure and functions; in Gabius H-J, S Gabius (eds): Glycosciences: Status and Perspectives. London, Chapman \& Hall, pp 201-222.

Laine, R.A. (1997) The information-storing potential of the sugar code; in Gabius H-J, S Gabius (eds): Glycosciences: Status and Perspectives. London, Chapman \& Hall, pp 1-14.

Lee, R.T., H.-J. Gabius, Y.C. Lee (1992) Ligandbinding characteristics of the major mistletoe lectin. J Biol Chem 267: 23722-23727.

Lee, R.T., H.-J. Gabius, Y.C. Lee (1994) The sugarcombining area of galactose-specific toxic lectin of mistletoe extends beyond the terminal sugar residue: Comparison with a homologous toxic lectin, ricin. Carbohydr Res 254: 269-276.

Lee, Y.C. (1997) Fluorescence spectrometry in studies of carbohydrate-protein interactions. J Biochem 121: 818-825.

Lee, Y.C., R.T. Lee (eds) (1994) Neoglycoconjugates. Preparation and Applications. San Diego, Academic Press.

Lian, L.Y., I.L. Barsukov, M.J. Sutcliffe, K.H. Sze, G.C.K. Roberts (1994) Protein-ligand interactions: Exchange processes and determination of ligand conformation and protein-ligand contacts. Methods Enzymol 239: 657-700.

Lotan, R., G.L. Nicolson (1979) Purification of cell membrane glycoproteins by lectin affinity chromatography. Biochim Biophys Acta 559: 329-376.
Lowe, J.B., P.A. Ward (1997) Therapeutic inhibition of carbohydrate-protein interactions in vivo. J Clin Invest 99: 822-826.

MacArthur, M.W., P.C. Driscoll, J.M. Thornton (1994) NMR and crystallography: Complementary approaches to structure determination. Trends Biotechnol 12: 149-153.

Mahal, L.K., C.R. Bertozzi (1997) Engineered cell surfaces: Fertile ground for molecular landscaping. Chem Biol 4: 415-422.

Mandal, D.K., C.F. Brewer (1993) Lectin-glycoconjugate cross-linking interactions; in Gabius H-J, S Gabius (eds): Lectins and Glycobiology. Berlin, Springer, pp 117-128.

Mann, P.L. (1988) Membrane oligosaccharides: Structure and function during differentiation. Int Rev Cytol 112: 67-96.

Mann, P.L., R.E. Waterman (1998) Glycocoding as an information management system in embryonic development. Acta Anat 161: 153-161.

Marrone, T.J., J.M. Briggs, J.A. McCammon (1997) Structure-based drug design: Computational advances. Annu Rev Pharmacol Toxicol 37: 71-90.

Montreuil, J. (1995) The history of glycoprotein research, a personal view; in Montreuil J, JFG Vliegenthart, H Schachter (eds): Glycoproteins. Amsterdam, Elsevier, pp 1-12.

Moothoo, D.N., J.H. Naismith (1998) Concanavalin A distorts the $\beta$-GlcNAc-1,2-Man linkage of GlcNAc-1,2- $\alpha-1,3-[\beta G l c N A c-1,2-$ $\alpha$-Man-1,6]-Man upon binding. Glycobiology 8: 173-181.

Ni, F. (1994) Recent developments in transferred NOE methods. Prog Nucleic Magn Reson Spectrosc 26: 517-606.

Pavelka, M. (1997) Topology of glycosylation - A histochemist's view; in Gabius H-J, S Gabius (eds): Glycosciences: Status and Perspectives. London, Chapman \& Hall, pp 115-120.

Pearlman, D.A. (1994) How is an NMR structure best defined? An analysis of molecular dynamics distance-based approaches. J Biomol NMR 4: 1-16.

Pérez, S., A. Imberty, J.P. Carver (1994) Molecular modeling: An essential component in the structure determination of oligosaccharides and polysaccharides. Adv Comput Biol 1: 147-202.

Peters, T., B.M. Pinto (1996) Structure and dynamics of oligosaccharides: NMR and modeling studies. Curr Opin Struct Biol 6: 710-720.

Peumans, W.J., E.J.M. van Damme (1995) The role of lectins in plant defence. Histochem J 27: 253-271

Poppe, L., C.-W. von der Lieth, J. Dabrowski (1990) Conformation of the glycolipid globoside head group in various solvents and in the micelle-bound state. J Am Chem Soc 112: 7762-7771.

Poppe, L., G.S. Brown, J.S. Philo, P.V. Nikrad, B.H. Shah (1997) Conformation of $\mathrm{sLe}^{\mathrm{x}}$ tetrasaccharide, free in solution and bound to E-, P-, and L-selectin. J Am Chem Soc 119: 1727-1736.

Rasmussen, K. (1997) How to develop force fields: An account of the emergence of potential energy functions for saccharides. J Mol Struct 395/396: 91-106.
Rhodes, J.M., J.D. Milton (eds) (1998) Lectin Methods and Protocols. Totowa, Humana Press.

Rice, K.G. (1997) Glycoconjugate-mediated drug targeting; in Gabius H-J, S Gabius (eds): Glycosciences: Status and Perspectives. London, Chapman \& Hall, pp 471-483.

Rini, J.M. (1995) Lectin structure. Annu Rev Biophys Biomol Struct 24: 551-577.

Rüdiger, H. (1997) Structure and function of plant lectins; in Gabius H-J, S Gabius (eds): Glycosciences: Status and Perspectives. London, Chapman \& Hall, pp 415-438

Rüdiger, H. (1998) Plant lectins - More than just tools for glycoscientists. Occurrence, structure and possible functions of plant lectins. Acta Anat 161: 130-152.

Schmidt, R.R. (1997) Strategies for chemical synthesis of carbohydrate structures; in Gabius H-J, S Gabius (eds): Glycosciences: Status and Perspectives. London, Chapman \& Hall, pp 31-53.

Sharon, N. (1993) Lectin-carbohydrate complexes of plants and animals: An atomic view. Trends Biochem Sci 18: 221-226.

Sharon, N. (1998) Glycoproteins now and then Acta Anat 161: 7-17.

Sharon, N., H. Lis (1987) A century of lectin research (1888-1988). Trends Biochem Sci 12: 488-491.

Sharon, N., H. Lis (1989) Lectins as cell recognition molecules. Science 246: 227-234.

Sharon, N., H. Lis (1997) Glycoproteins: Structure and function; in Gabius H-J, S Gabius (eds): Glycosciences: Status and Perspectives. London, Chapman \& Hall, pp 133-162.

Siebert, H.-C., R. Adar, R. Arango, M. Burchert, H. Kaltner, G. Kayser, E. Tajkhorshid, C.-W. von der Lieth, R. Kaptein, N. Sharon, J.F.G. Vliegenthart, H.-J. Gabius (1997a) Involvement of laser photo CIDNP (chemically induced dynamic nuclear polarization)-reactive amino acid side chains in ligand binding by galactoside-specific lectins in solution. Similarities in the role of tryptophan/tyrosine residues for ligand binding between a plant agglutinin and mammalian/avian galectins and the detection of an influence of single-site mutagenesis on surface presentation of spatially separated residues. Eur J Biochem 249: 27-38.

Siebert, H.-C., M. Gilleron, H. Kaltner, C.-W. von der Lieth, T. Kožár, N.V. Bovin, E.Y. Korchagina, J.F.G. Vliegenthart, H.-J. Gabius (1996) NMR-based, molecular dynamics- and random walk molecular mechanics-supported study of conformational aspects of a carbohydrate ligand Gal $31-2 \mathrm{Gal} \beta 1-\mathrm{R}$ for an animal galectin in the free and in the bound state. Biochem Biophys Res Commun 219: 205-212.

Siebert, H.-C., C.-W. von der Lieth, M. Gilleron, G. Reuter, J. Wittmann, J.F.G. Vliegenthart, H.-J. Gabius (1997b) Carbohydrate-protein interaction; in Gabius H-J, S Gabius (eds): Glycosciences: Status and Perspectives. London, Chapman \& Hall, pp 291-310. 
Siebert, H.-C., C.-W. von der Lieth, R. Kaptein, J.J. Beintema, K. Dijkstra, N. van Nuland, U.M.S Soedjanaatmadja, A. Rice, J.F.G. Vliegenthart, C.S. Wright, H.-J. Gabius (1997c) Role of aromatic amino acids in carbohydrate binding of plant lectins. Laser photo CIDNP (chemically induced dynamic nuclear polarization) study of hevein domain-containing lectins. Proteins 28: 268-284.

Simon, P.M. (1996) Pharmaceutical oligosaccharides. Drug Discov Today 1: 522-528.

Solís, D., J. Jimenez-Barbero, M. Martin-Lomas, T. Diaz-Mauriño (1994) Probing hydrogenbonding interactions of bovine heart galectin-1 and methyl $\beta$-lactoside by use of engineered ligands. Eur J Biochem 223: 107-114.

Solís, D., A. Romero, H. Kaltner, H.-J. Gabius, T. Diaz-Mauriño (1996) Different architecture of the combining sites of two chicken galectins revealed by chemical-mapping studies with synthetic ligand derivatives. J Biol Chem 271: 12744-12748.

Sowdhamini, R., S.D. Ruffino, T.L. Blundell (1994) The construction and use of databases of protein domain topologies and templates. Chemtracts 5: 291-306.

Spicer, S.S., B.A. Schulte (1992) Diversity of cell glycoconjugates shown histochemically: A perspective. J Histochem Cytochem 40: 1-38.

Stowell, C.P., Y.C. Lee (1980) Neoglycoproteins: The preparation and application of synthetic glycoproteins. Adv Carbohydr Chem Biochem 37: 225-281.

Stryer, L. (1978) Fluorescence energy transfer as a spectroscopic ruler. Annu Rev Biochem 47: 819-846.
Varki, A. (1996) 'Unusual' modifications and variations of vertebrate oligosaccharides: Are we missing the flowers for the trees? Glycobiology 6: 707-710.

Varki, A. (1998) Factors controlling the glycosylation potential of the Golgi apparatus. Trends Cell Biol 8: 34-40

Varki, A., J. Marth (1995) Oligosaccharides in vertebrate development. Semin Dev Biol 6: 127-138.

Vasta, G.R. (1992) Invertebrate lectins: Distribution, synthesis, molecular biology and function; in Allen HJ, EC Kisailus (eds): Glycoconjugates: Composition, Structure and Function. New York, Dekker, pp 543-634.

Villalobo, A., H.-J. Gabius (1998) Signaling pathways for transduction of the initial message of the glycocode into cellular responses. Acta Anat 161: 110-129.

von der Lieth, C.-W. (1997) The role of $\mathrm{Ca}^{2+}$ in the binding of carbohydrates to C-type lectins as revealed by molecular mechanics and molecular dynamics calculations; in Banci L, P Comba (eds): Molecular Modeling and Dynamics of Bioinorganic Systems. Dordrecht, Kluwer, pp 167-190.

von der Lieth, C.-W., E. Lang, T. Kožár (1997a) Carbohydrates: Second-class citizens in biomedicine and in bioinformatics?; in Hofestädt R, T Lengauer, M Löffler, D Schomburg (eds): Bioinformatics. Berlin, Springer, pp 147-155. von der Lieth, C.-W., T. Kožár, W.E. Hull (1997b) A (critical) survey of modeling protocols used to explore the conformational space of oligosaccharides. J Mol Struct 395/396: 225-244.

von Itzstein, M., P.M. Colman (1996) Design and synthesis of carbohydrate-based inhibitors of carbohydrate-protein interaction. Curr Opin Struct Biol 6: 703-709.
Wagner, G., S.G. Hyberts, T.F. Havel (1992) NMR structure determination in solution: A critique and comparison with X-ray crystallography. Annu Rev Biophys Biomol Struct 21: 167-198.

Weis, W.I., K. Drickamer (1996) Structural basis of lectin-carbohydrate recognition. Annu Rey Biochem 65: 441-473.

Witczak, Z.J. (1997) Carbohydrates as new and old targets for future drug design; in Witczak ZJ, KA Nieforth (eds): Carbohydrates in Drug Design. New York, Dekker, pp 1-37.

Woods, R.J. (1996) The application of molecular modeling techniques to the determination of oligosaccharide solution conformations; in Lipkowitz K, DB Boyd (eds): Reviews in Computational Chemistry, New York, VCH Publishers, vol 9, pp 129-165.

Woods, R.J., R.A. Dwek, C.J. Edge, B. Fraser-Reid (1995) Molecular mechanical and molecular dynamical simulations of glycoproteins and oligosaccharides. J Phys Chem 99: 3832-3846

Zanetta, J.-P. (1997) Lectins and carbohydrates in animal cell adhesion and control of cell proliferation; in Gabius H-J, S Gabius (eds): Glycosciences: Status and Perspectives. London, Chapman \& Hall, pp 439-458.

Zanetta, J.-P. (1998) Structure and functions of lectins in the central and peripheral nervous system. Acta Anat 161: 180-195.

Zopf, D., S. Roth (1996) Oligosaccharide anti-infective agents. Lancet 347: 1017-1021.

Zschäbitz, A. (1998) Glycoconjugate expression and cartilage development of the cranial skeleton. Acta Anat 161: 254-273 